\title{
1 OBERSTE BEHÖRDEN DES REICHS, DER LÄNDER, REICHSGAUE UND PROVINZEN UND FÜR AUSWÄRTIGE ANGELEGENHEI- TEN
}

\author{
$1.1 \quad$ Oberste Reichsbehörden
}

\subsubsection{E Präsidialkanzlei des Führers und Reichskanzlers}

ZDM MO, Best. 1413; BA DH, Best. ZJ, ZB 5

Der Moskauer Teilbestand (53 Bde, 1921-1944) enthält vor allem Akten über die Verleihung der Ostmarkmedaille (12 Bde, 1938-1943), die Polizei-Dienstauszeichnung (3 Bde, 1942) und andere Auszeichnungen (4 Bde), u. a. an Eisenbahner in den Ostgebieten, ferner einzelne politische Berichte (2 Bde, 1935-1937) und Unterlagen über die Vertretung auf der Londoner Abrüstungskonferenz (1933), die Einstellung von Verfahren wegen Mißhandlung von Gefangenen (1935-1936), Rassen- und Bevölkerungspolitik (19351936) sowie eine Liste der Mitarbeiter (1942-1943). In Dahlwitz-Hoppegarten befinden sich in Mischbeständen Unterlagen über die Ernennung von Offizieren und Beamten, wahrscheinlich auch der Ordnungs- und Sicherheitspolizei, und über die Verleihung der Olympia-Medaille, von SS-Dienstauszeichnungen und Kriegsverdienstkreuzen in nicht ermitteltem, aber erheblichem Umfang (32 lfm).

\subsubsection{E Reichskanzlei}

ZDM MO, Best. 1235

Die nach Moskau gelangten Akten (117 Bde, 1917-1944) betreffen u. a.: Gesetzgebung (5 Bde, 1940-1944), internationale Abkommen und Noten (3 Bde, 1933-1940), Personalangelegenheiten des Reichssicherheitsdienstes (10 Bde, 1936-1944), Beförderungen im Reichsinnen- und in anderen Ministerien (3 Bde, 1933-1944) und von Offizieren (2 Bde, 1938-1942), die Verleihung der Sudetenmedaille, des KVK und anderer Auszeichnungen (5 Bde, 1939-1943), den Neubau der Reichskanzlei (2 Bde, 1939). Sie enthalten ferner Briefe aus der Bevölkerung an Hitler (4 Bde, 1934-1945), auch an Lammers, und belegen Einzelfälle von Hitler gewährter Unterstützungen (4 Bde, 1934-1942). Vorhanden sind außerdem Tagespläne (1944), Listen der Gratulanten zu Hitlers Geburtstag 1940 und für den Empfang von Kommunalpolitikern (1935-1942), ein Gestapobericht über die Stimmung an der Saar (1934), Vorgänge über die Verhandlungen mit Großbritannien (1932-1935), über Sozialpolitik, Studenten und Verwaltungsakademien (aus der Tätigkeit von Lammers) und über die Finanzierung des Ankaufs von Kunstwerken (1937-1945).

\subsubsection{E Vizekanzlei von Papen}

ZDM MO, in Best. 703

Im Nachlaß Papens befinden sich einige nicht sehr umfangreiche Akten (10 Bde, 19331934), die möglicherweise aus der Vizekanzlei stammen (z. T. nach Verfilmung an das Außenministerium der Sowjetunion abgegeben). Dazu gehören Berichte über Papens Italienreise 1933, über die Stimmung in der NSDAP und Unterlagen über den Konflikt mit Schleicher, Reichsreform, Wirtschaftspolitik, die Marburger Rede und die Kritik an der Rassenpolitik. 


\subsubsection{Reichsstatthalter}

\subsubsection{Reichsstatthalter im Altreich}

Die Überlieferung des Reichsstatthalters in Braunschweig und Anhalt beschränkt sich auf Vorschläge zur Ernennung von Beamten (334 Bde, 1938-1945) und Personalakten von Polizeibeamten (475 Bde, 1940-1943, beides BA DH, vgl. auch Bd. 1, S. 7), in Sachsen ist sie mit Schriftgut der Staatskanzlei vereinigt (vgl. unten Abschnitt 1.2), so $\mathrm{da} B$ nur folgende Bestände verbleiben, zu denen noch einzelne Personalvorgänge über thüringische und sächsische Beamte (BA DH) kommen:

\subsection{Reichsstatthalter in Thüringen, Weimar}

WE

Der Bestand (insgesamt 5 lfm, 1933-1945) enthält aus dem Büro des Reichsstatthalters Fritz Sauckel u. a. an ihn gerichtete Gesuche (62 Bde, 1933-1945) und Reden, Aufsätze und Aufrufe (8 Bde, 1933-1945). Vorhanden sind auch Akten über Geschäftsordnung, Haushalt, Gebäude (13 Bde, 1933-1945), Geschäftsverteilungspläne auch der Reichsverwaltung (16 Bde, 1933-1945), dabei Geheimbefehle anläßlich der Volksabstimmung 1938), Einzelpersonalakten (24 Bde, 1933-1945). Weitere Unterlagen betreffen die Verwaltung Thüringens (21 Bde, 1933-1944, darin: Reden des Staatssekretärs Walter Ortlepp), Polizeiangelegenheiten (24 Bde, 1930-1944, darin: 9 Bde Erlasse, Weisungen und Rundverfügungen des Reichsführers SS und Chefs der Deutschen Polizei, 1933-1943), Tätigkeit der Gestapo (mit Berichten, 17 Bde, 1934-1944), Angelegenheiten der NSDAP (15 Bde, 1933-1944), öffentlichen Dienst (28 Bde, 1933-1945), Förderung der Industrie, Arbeitsbeschaffung (24 Bde, 1933-1944), Verkehr (8 Bde, 1939-1944), Wasserwirtschaft (4 Bde, 1933-1943), Aufbau und Organisation der Kriegswirtschaft (10 Bde, 1939-1942), Kriegswirtschaftsmaßnahmen (23 Bde, 1939-1945), Bewirtschaftung von Waren (31 Bde, 1939-1945), allgemeinbildende und Fachschulen (18 Bde, 1933-1944), Universität Jena und andere Hochschulen (31 Bde, 1933-1945, vor allem Besetzung einzelner Lehrstühle), Theater, Literatur, Kunst (16 Bde, 1933-1944), Institute, Vereine, Gesellschaften (40 Bde, 1933-1945), Natur- und Denkmalschutz (9 Bde, 1933-1942), Kirchen (5 Bde, 1934-1936), ReichsverteidigungsausschuB (14 Bde, 19361945), Volkssturm (2 Bde, 1945), Luftschutz, Umquartierungen (11 Bde, 1933-1945), Arbeitseinsatz (2 Bde, 1942/43).

Ergänzungsüberlieferung bieten die Akten des Verfahrens gegen Sauckel als Generalbevollmächtigter für den Arbeitseinsatz (vgl. Bd. 1, S. 408) vor dem Internationalen Militärgerichtshof Nürnberg.

\subsection{Reichsstatthalter in Mecklenburg, Schwerin}

SN, Best. 2275

Aus dem Amt des bis 1937 auch für Lübeck zuständigen Reichsstatthalters und Gauleiters Friedrich Hildebrandt blieben nur Splitter erhalten $(0,5 \mathrm{lfm})$, die neben wenigen Akten hauptsächlich Pressematerial enthalten.

\subsubsection{Reichsstatthalter und Gauselbstverwaltung in eingegliederten Gebieten}

Nachdem zunächst alle österreichischen Bundesländer einem Reichsstatthalter unterstellt worden waren, wurden sie durch das Ostmarkgesetz vom 14. April 1939 in Reichsgaue unter dem jeweiligen Gauleiter der NSDAP als Reichsstatthalter umgewandelt, wobei 
Vorarlberg mit Tirol, das Burgenland mit Niederösterreich vereinigt wurden. Gleichzeitig wurde der größte Teil der durch das Münchener Abkommen annektierten sudetendeutschen Gebiete zum Reichsgau Sudetenland zusammengefaßt. In Polen wurden durch Verordnung vom 8. Oktober 1939 für das Gebiet der Freien Stadt Danzig und die ehemalige preußische Provinz Westpreußen der Reichsgau Danzig-Westpreußen, für das nach Osten erweiterte Gebiet der ehemaligen Provinz Posen der Reichsgau Wartheland gebildet. Nach dem Vorbild der preuBischen Provinzialverwaltungen wurde für die Reichsgaue zugleich eine Gauselbstverwaltung geschaffen, an deren Spitze ein Gauhauptmann den Reichsstatthalter vertrat, während für seine Vertretung in der Reichsverwaltung ein Regierungspräsident bestellt wurde. Das bei der Gauselbstverwaltung, insbesondere den Gaukämmereien, entstandene Schriftgut ist, soweit erhalten, zusammen mit der staatlichen Überlieferung behandelt.

\subsection{Reichskommissar für die Wiedervereinigung Österreichs mit dem Deutschen Reich AdR, Best. 04R001/1 und 04R002/1}

Die Akten des am 22. April 1938 zum Reichskommissar bestellten Gauleiters der Saarpfalz und ehemaligen Reichskommissars für die Rückgliederung des Saargebietes Josef Bürckel, dessen Kompetenzen sich auf ganz Österreich und die im Herbst 1938 damit verbundenen böhmischen und mährischen Kreise erstreckten, sind offenbar fast vollständig vorhanden ( $425 \mathrm{Kts}$ ); sie reichen mit Nachakten bis August 1940, enthalten aber auch Vorgänge aus der Bürckel im März 1938 übertragenen Funktion als Beauftragter des Führers für die Volksabstimmung in Deutschösterreich. Die Sachakten betreffen:

Personalangelegenheiten, Beamtenwesen, Volksabstimmung, Auswärtige Angelegenheiten (diplomatische Vertretungen, Grenzverkehr), Vereinsangelegenheiten, Polizei (dabei Mitteilungen der Kriminalpolizeileitstelle Wien, Januar-August 1940), Gemeindewesen, Finanzen und Steuern, Zölle, Bank-, Börsen- und Kreditwesen, Bergbau, Verleihung von Auszeichnungen, Justizwesen, Rassegesetzgebung, Arbeits- und Sozialrecht, Löhne und Tarife, Versicherungsrecht, Fürsorgewesen, Pensionsrecht, Wirtschaft, Energiewirtschaft, Tabakregie, Arisierungen, Preisbildung, Kammerangelegenheiten, Forstwesen, Land- und Holzwirtschaft, Raumordnung, Städtebau, Wohn- und Siedlungswesen, Gesundheitswesen, Krankenkassen, Propaganda, Film- und Kinoangelegenheiten, Rundfunk, Kunst und Kultur, Theater, Musik, Presse, Schulwesen, Hochschulangelegenheiten, Kultuswesen, Verkehr, Eisenbahnen, Luft- und Schiffahrt, Wehrmacht und zivile Reichsverteidigung, Reichsarbeitsdienst, Sport, NSDAP (u. a. Sammlungen, NS-Presse), Deutsche Arbeitsfront.

Ein Teilbestand (Korrespondenz Bürckels, $107 \mathrm{Kts}$ ) enthält hauptsächlich Zuschriften aus der Bevölkerung, die häufig zu Behördenvorgängen führten, die jedoch nicht erkennbar werden, weil als „Leitname“ zumeist jener des Einsenders dient, so daß ein Zugriff auf die Information über die eigentlich betroffene Person und den Sachbetreff (z. B. Arisierung oder Schutzhaftangelegenheit) nicht möglich ist.

Akten (44 Bde, 1938-1940) u. a. über die Wirtschaft in Österreich, Personalmaßnahmen (Korrespondenz Bürckels mit Göring über die Ernennung eines Gauleiters in Wien), Mobilmachungsplanung, Staatsangehörigkeit, Ausländer, Juden, katholisch-theologische Fakultäten, Stift Klosterneuburg (Errichtung eines „Fonds der Deutschen Mutter") sind als Mikrofilm auch im BA KO vorhanden (Best. R 104 F).

Einen eigenen Bestand bildet das Schriftgut (ca. $2200 \mathrm{Kts}$, 1938-1944) des von Bürckel ernannten 


\section{Stillhaltekommissars für Vereine, Organisationen und Verbände}

AdR, Best. 04R003/1 und 04R004/1

In dieser Funktion sollte Reichsamtsleiter Albert Hoffmann alle österreichischen Organisationen nach Sicherung ihres Vermögens durch kommissarische Verwaltung entweder nach nationalsozialistischen Grundsätzen durch personelle oder organisatorische $\mathrm{Maßnahmen}$ gleichschalten, in bestehende NS-Organisationen eingliedern oder auflösen; weitgehend ausgenommen waren Genossenschaften und andere wirtschaftlich tätige Organisationen. In Konkurrenz mit der Gestapo befaßte er sich auch mit jüdischen und politischen Vereinen, Logen und Sekten, mit Stiftungen und Fonds war zugleich das Ministerium für innere und kulturelle Angelegenheiten befaßt (Nachfolgeakten Bundeskanzleramt). Die Akten, die die Überlieferung der 1938 errichteten Zweigstelle Reichenberg für das Sudetenland einschließen, sind überwiegend 1938 und 1939 entstanden und in folgende Gruppen gegliedert:

Vereine für Beamte und Behördenangestellte, Lehrervereinigungen, Studentische Verbindungen und akademische Vereinigungen, Wirtschafts- und Gewerbeorganisationen, Jagdvereine, Angestelltenorganisationen, -vereine und -verbände, Arbeiterorganisationen, -vereine und -verbände, landwirtschaftliche Organisationen (Reichsnährstand), berufsständische Vereine wie Ärzte-, Juristen- und Apothekerverbände, technische Vereinigungen, Sport- und Turnvereine, Wandervereine, landsmannschaftliche Vereinigungen, Kraftfahrorganisationen, Luftsportvereine, kulturelle Vereine, Frauenvereine und -organisationen, Jugendvereine und -organisationen, Frontsoldaten- und Kriegervereine, Tierschutzvereine, Wohlfahrtsvereinigungen, Sterbevereine, Haus- und Grundbesitzervereinigungen und Mieterverbände, Freimaurerorganisationen, katholische und altkatholische Vereine, Organisationen und Verbände, karitative Vereine, Eltern- und Schulvereine, evangelische Vereine, jüdische Vereine, Sekten, Verschiedenes (darunter Kartenund Schachspielvereine, Amateurphotographenvereine, Philatelistenvereine, Ritterschaften und Fremdenverkehrsvereine), gesundheitliche Vereine, politische und außerösterreichische Vereine, wissenschaftliche Vereine, Kulturkammer (darunter Bildende Kunst, Bühne und Theater, Komponisten, Autoren und Verleger, Musikvereine, Gesangvereine, Presse, Film, Schriftsteller), Kriegsopfervereine und -verbände, Stenographenvereine, Stiftungen und Fonds, innerbetriebliche Vereine. Das „Amtliche Nachrichtenblatt“ des Stillhaltekommissars mit einer eigenen Ausgabe für das Sudetenland ist im BA KO überliefert (NSD 38, 40 bzw. 48 Nrn, 1938-1940).

Lit.: GUIDES to German Records, vol. 5, S. 8-15. - H. PFEIFER: Die Ostmark. 1941. - G. BOTZ: Die Eingliederung Österreichs in das Deutsche Reich. 1976. - L. MIKOLETZKY: Josef Bürckels Dienststelle und die Steiermark 1938/39.

\subsection{Reichsstatthalter in Österreich, Wien}

AdR, Best. 04R302/1(Präsidium) und O4R303/1

Der letzte österreichische Bundeskanzler Arthur SeyB-Inquart war ab 15. März 1938 als Reichsstatthalter in Österreich für alle bisherigen Bundesländer zuständig. Er bediente sich dafür des bisherigen Bundeskanzleramtes, das im Juni 1938 in der Weise umgestaltet wurde, da $B$ aus der ehemaligen Präsidialabteilung die Reichsstatthaltereiabteilungen I und II hervorgingen und eine Abteilung III (Leiter Kajetan Mühlmann) für kulturelle Angelegenheiten neu geschaffen wurde. Die übrigen Abteilungen des Bundeskanzleramtes wurden zu den Abteilungen I und II des Ministeriums für innere und kulturelle Angelegenheiten, die personellen und materiellen Agenden der ehemaligen Generaldirektion für die öffentliche Sicherheit übernahm dessen Abteilung III. Die Akten sowohl 
der Reichsstatthalterei wie auch des Ministeriums erliegen unter den gleichen Signaturen (durch Zahlenschlüssel nach Betreffen geordnet) jeweils im Anschluß an die Akten des Bundeskanzleramtes. Die Akten der Abteilungen III beider Behörden bilden eigene Bestände, soweit sie nicht - z. T. erst nach 1945 - vernichtet wurden. Die Überlieferung endet mit der fortschreitenden Ausgestaltung der Verwaltung der neuen Reichsgaue spätestens mit 1940.

Die Akten (insgesamt ca. $880 \mathrm{Kts}$ ) stammen aus folgenden Sachgruppen: Staatssymbole, Behördenorganisation, Archiv- und Bibliothekswesen, Amtsgebäude, Personal-, Besoldungs- und Disziplinarangelegenheiten, Staatsbürgerschaft, Matriken, Legitimation, Adoption, Namensgebung, Eheangelegenheiten, Kommunalangelegenheiten, Heimatrecht, Wirtschaftsgesellschaften, Kriegsgräber, Stiftungen und Fonds, Landesverfassung und Landesangelegenheiten, Volkszählung und Einwohnerverzeichnis, Fürsorgewesen, Gesetzgebung, Rechtsangleichung, Verleihung von Auszeichnungen.

Eigene Serien bilden Akten des Inspekteurs der Ordnungspolizei beim Reichsstatthalter für Österreich, der „Übergangsregistratur“ der ehemaligen Abteilung 1 der Generaldirektion für die öffentliche Sicherheit (Polizeiangelegenheiten), der Abteilung III des Ministeriums für innere und kulturelle Angelegenheiten (Gruppe Ordnungspolizei - Amt für Verwaltung und Recht) und der Abteilung III des Reichsstatthalters (Kunst- und Kulturangelegenheiten) über Ausstellungen, Museen, Erwerb von Kunstgegenständen, Kunstförderung, Musik, Theater, Schulen, Denkmalschutz und Archivwesen (1938-1940) sowie über Stiftungen und Fonds.

Der Nachlaß Seyß-Inquarts (BA KO) enthält aus den Jahren 1937/38 Korrespondenz (4 Bde, dabei Fernschreiben), Protokolle von Sitzungen, Reden und einzelne Sachakten u. a. über Korruptionsfälle, Neugliederung des Landes, Minderheiten, Rundfunk, HJ und die Konsularakademie. In Dokumenten und Protokollen des Verfahrens gegen ihn vor dem Internationalen Militärgerichtshof in Nürnberg, das hauptsächlich seine Tätigkeit als Reichskommissar in den Niederlanden behandelte, ist Ergänzungsüberlieferung vorhanden.

\subsection{Reichsstatthalter in Wien}

AdR, Best. 04R007/1

Mit geringen Ausnahmen enthält der Bestand nur Akten aus der Amtszeit des Reichsstatthalters Baldur von Schirach, dem am 7. August 1940 die Aufsicht über den mit dem Stadtgebiet identischen Reichsgau Wien übertragen wurde. Sie stammen vor allem von jenen Abteilungen, deren Sitz sich im ehemaligen österreichischen Bundeskanzleramt befand, und sind wie folgt gegliedert (insgesamt ca. $600 \mathrm{Kts}$ ):

- Hauptbüro Schirach: Neben Gesuchen um Intervention in Einzelfällen und Korrespondenzen betreffend Wohnungsangelegenheiten, Auszeichnungen, Rassenfragen, Kunst, Kultur und Rüstung, auch Schriftwechsel von Mitarbeitern, der teilweise aus Schirachs weiterer Funktion als Reichsleiter für die Jugenderziehung der NSDAP herrührt (u. a. Europäisches Jugendwerk, Hitlerjugend, Reichsjugendführung, Kriegslyrik) oder seine persönlichen Interessen betrifft (Südosteuropagesellschaft, Wiener Messen, kulturelle Angelegenheiten und Veranstaltungen); dabei befinden sich auch Tagesberichte der Staatspolizeileitstelle Wien (September 1940-August 1943), des Schutzpolizeikommandos Wien (Oktober-Dezember 1939) und der Kriminalpolizeileitstelle Wien (lückenhaft, Oktober 1940-August 1941).

- Z (Zentralbüro)-Haushalt (41 Kts): Budgetangelegenheiten sämtlicher unterstehenden Institutionen. 
- Z-Pers (92 Kts): Akten in Personalangelegenheiten, die ein umfassendes Bild sämtlicher Aspekte des öffentlichen Dienstes in den Jahren 1940-1945 bieten.

- Z-Org bzw. Ib-Org, zentrales Organisationsreferat (10 Kts): Sie betreffen innere Organisation der Behörde und ebenfalls Beamte.

- Z-R = Zentrales Rechtsreferat (37 Kts betr. Rechtsangleichung und Verwaltungsverfahren).

- Z-RV = Reichsverteidigung (10 Kts, fast nur betr. Uk-Stellungen von Lehrpersonal).

- TK (3 Kts betr. Totaler Kriegseinsatz, vor allem Maßnahmen zur Verwaltungsvereinfachung).

- Obere Siedlungsbehörde (15 Kts): Unterlagen über Arisierung landwirtschaftlicher Liegenschaften.

- Z-RO = Generalreferat für Raumordnung (23 Kts): Akten über Planung und Bau von Verkehrslinien, Wohnungen und Industrieanlagen.

- Ia VB (9 Kts): Restbestand über Vereins-, Fonds- und Stiftungs- und Kulturangelegenheiten mit Vor- und Nachakten, u. a. aber mit Unterlagen zum jüdischen Auswanderungsfonds.

- Ia Pol und ISPol (140 Kts): hauptsächlich allgemeines Material (Vorschriften) betreffend Polizeiverwaltung, -organisation, -bauten und -personal, aus den letzten Kriegsjahren auch Unterlagen über volksdeutsche Flüchtlinge aus der Slowakei, Serbien, Ungarn und Kroatien und wesentliche Quellen für die Veränderung des Alltagslebens unter Einfluß des Krieges.

- Abteilung IIId GA und GM, Gewerbeaufsicht und Staatlicher Gewerbearzt (ca. 30 Kts, 1938-1945, in Best. 03R109/1, mit Vorakten des Ministeriums für Wirtschaft und Arbeit): Unterlagen über Arbeitsschutz, Schutz der Frauen, Jugendlichen und Kinder, Unfall- und Gefahrenschutz, Arbeitszeitordnung, Lohnzahlung, kriegswirtschaftliche Aufgaben), Aufsicht über die nachgeordneten Gewerbeaufsichtsämter, jeweils auch für Niederdonau, gesundheitlicher Arbeitsschutz (Gewerbehygiene) und ärztliche Gewerbeaufsicht für die gesamte Ostmark mit einer allgemeinen Aktenserie, Personalunterlagen der Inspektionsärzte und Vorgängen über Kraftfahrwesen, Dampfkessel, Jugendschutzgesetz und Arbeitszeitordnung, Untersuchungen chemischer Produkte, Berufserkrankungen (u. a. Silikose, Augenerkrankungen), Überprüfung einzelner Firmen, Hygieneuntersuchungen, zusätzliche Lebensmittelzuteilung für gesundheitlich gefährdete Arbeiter.

- Abteilung III RWH, Reichswirtschaftshilfe (ca. $300 \mathrm{Kts}, 1938-1945$ ): Akten über die seit 1938 bewilligten ,reichsverbürgten Kleinkredite“ und andere, teilweise sehr bedeutende „reichsverbürgte Kredite“, Konsortialkredite und Reichsdarlehen mit einer Serie über die gewährten Kleinkredite und abgelehnten Anträge für die Wiener gewerbliche Wirtschaft und das Gast- und Schank- und Fremdenbeherbergungsgewerbe, während die Akten über die sonstigen Kredite Firmen in ganz Österreich einschließlich der angegliederten Sudetengebiete betreffen. Ein großer Teil der Kredite wurde in Verbindung mit Arisierungen bewilligt. Die zumeist beiliegenden wirtschaftlichen Prüfberichte geben Auskunft über den Status der Firma und oft über die Firmengeschichte, u. a. mit Unterlagen für die Geschichte der Rüstungsindustrie in Österreich. Über die Antragsteller liegen zahlreiche politische Beurteilungen vor.

- Abteilung IIId W und WSF, Wohnbauförderung, Wohn- und Siedlungsfonds (ca. 100 Kts, 1938-1944, in Best. 03R107/1, mit Vorakten des Ministeriums für Wirtschaft und Arbeit: Akten über Förderung von Wohnungen und Kleinwohnungen durch Bürgschaften, Zuschüsse, Darlehen; Verwaltung der fondseigenen Häuser; Erwerb von Liegenschaften; 
Gesetz über die Anforderung von Wohnungen und Geschäftsräumen; Beseitigung von Elendswohnungen jeweils in sämtlichen Reichsgauen der Ostmark.

- Abteilung V - Bauwesen (3 Kts): Splitterbestand mit Parallelüberlieferung zu den Reichsbauämtern, betrifft Organisation und einige wenige einzelne Bauvorhaben.

Gesondert (im Bestand 02R206/2) sind Akten des Generalreferats für Kunstförderung, Staatstheater, Museen und Volksbildung als Vorakten des Kunstsektion des Unterrichtsministeriums (ca. $35 \mathrm{Kts}, 1940$-1945) vorhanden. Sie betreffen u. a. die Akademien für angewandte und der bildenden Künste, die Musikakademie, Vereine, Denkmalamt, Kunstförderung und Ankauf von Kunstwerken, Ausstellungen, das Museum für Völkerkunde, die Österreichische Galerie, die Museen für angewandte Kunst und für Volkskunde, das Technische, Kunsthistorische, Naturhistorische Museum, Kunsthochschulen, die Hofmusikkapelle und die Hofburg; in sehr geringem Ausmaß enthalten sie auch Unterlagen über die Bergung von Kulturgut durch Einlagerung in Bergwerksstollen im Salzkammergut.

Ergänzungsüberlieferung liegt in den Akten des Verfahrens gegen Schirach vor dem Internationalen Militärgerichtshof in Nürnberg vor.

Lit:: G. BOTZ: Wien vom „AnschluB“ zum Krieg. 1988. - ders.: Von der Bundeshauptstadt zum Reichsgau. 1975. - P. CSENDES: Die Wiener Stadtverwaltung im März 1938 und ihre Entwicklung unter der nationalsozialistischen Herrschaft. 1978. - B. v. SCHIRACH: Ich glaubte an Hitler. 1967.

\subsection{Reichsstatthalter in Kärnten, Klagenfurt}

$\mathrm{KL}$

Die bei der Verwaltungsreform von 1925 eingeführte Verteilung der gesamten Amtstätigkeit der Landesregierung auf mehrere Kanzleistellen, die im wesentlichen der jeweiligen Referatsaufteilung entsprachen und sich mit dieser änderten, blieb nach dem „Anschluß" bestehen; auf die Landeshauptleute bzw. Reichsstatthalter und Gauleiter Hubert Klausner (1938-1939) und (stellvertretend) Franz Kutschera (1940-1941), deren Funktionen jedoch vom Regierungspräsidenten und Gauhauptmann Wladimir von Pawlowski ausgeübt wurden, folgte ab November 1941 Friedrich Rainer (bis 1944). Die Kanzleistellen legten überwiegend chronologisch geordnete und durch einen jährlichen Index erschlossene Betreffserien an, zum kleineren Teil wurden aber auch Selekte zu einzelnen Sachgebieten gebildet. Reichsdeutsche Aktenpläne wurden nur ganz vereinzelt von Unterabteilungen (z. B. Sanität) eingeführt. Der bisher vom Kärntner Landesarchiv übernommene Bestand hat folgende Gliederung:

- Präsidialabteilung (= Kanzleistelle A): Lediglich die Akten des Jahrgangs 1938 sind vorhanden. In der allgemeinen Serie (28 Bde) betreffen sie alle Kompetenzen des Präsidiums: Zentrale Behördenkoordination, Dienstbetrieb, Personalangelegenheiten, Dienstzeiten, Gebühren; Feiern und Feste, Wappen und Fahnen, Wahlen (Volksabstimmung vom 10. 4. 1938), Amtsgebäude; Auslandsbeziehungen, Kontakte zu anderen Ländern, zu Partei- und Sicherheitsdienststellen, Paßwesen, Grenzangelegenheiten, slowenische Minderheit; Versammlungen, Vereine und Verbände; Stiftungen, Sammlungen (u. a. Winterhilfswerk) und Subventionen, Film und Theater; Maßnahmen aus Anlaß der NSMachtübernahme und „Wiedervereinigung“, Wiedergutmachung für Nationalsozialisten; Luftschutz und Katastrophenvorsorge. Die Sachakten (135 Bde) dokumentieren die Abwicklung der vom Stillhaltekommissar angeordneten Auflösung oder Gleichschaltung mehrerer hundert Vereine (mit Vorakten seit etwa 1860), doch fehlen die Akten über alle fortbestehenden Vereine, da sie 1939 an die Gestapo abgegeben und vermutlich 1945 vernichtet wurden. Die Präsidialakten der Jahre 1939-1945 befinden sich noch bei 
der Landesregierung, doch umfassen sie infolge großer Kriegs- und Nachkriegsverluste nur wenige Faszikel.

- Kanzleistelle B: Die Allgemeine Aktenreihe für die Jahre 1938 und 1939 (36 Bde) stammt aus den Fachbereichen: Matrikenwesen (Personenstandsrecht, Standesämter, Ehescheidungen, Blutschutzgesetz usw., ab 1940: Kanzleistelle J); Kultus (Pfarren, Patronate, Priesterseminar, Kirchenbeitragsordnung, evangelische Kirche, israelitische Kultusgemeinde, Kirchenaustritte, ab 1940: Kanzleistelle J); Gewerbe (Konzessionen, Förderung, Gewerbekammer, jüdische Betriebe, Arisierung), Tankstellen, Eisenbahnen, Märkte und Messen, Post und Postkraftwagen; Straßenverkehr (ab 1940: Kanzleistelle F), für die Zeit von 1940 bis 1945 (28 Bde) nur noch aus den Kompetenzen für Gewerbe, Tankstellen, Eisenbahnverkehr, Märkte und Messen, dafür zusätzlich (vorher Kanzleistelle G) für Sparkassen, Jagd und Fischerei, landwirtschaftliche Fachschulen.

- Kanzleistelle C: Die Akten der erst 1942 aus einzelnen Kompetenzbereichen der Kanzleistelle J neu geschaffenen Stelle betreffen in der Allgemeinen Serie (150 Bde) Personenstandswesen (Eheschließung, Namensänderung), Kultus, Stiftungssachen und alle Staatsbürgerschaftsangelegenheiten, in der Sachaktenreihe (18 Bde) vor allem Religionsaustrittsstatistik, Ehrenzeichen der Deutschen Mutter, Erfassung der Volksdeutschen in den Ostgebieten und im Protektorat, Wehrerfassung, Kriegsverdienstkreuze, Pflege und Förderung deutschen Volkstums, Kriegssterbefälle (Erhebung 1946).

- Kanzleistelle D: Die allgemeine Aktenreihe (21 Bde, 1938-1940)) betrifft vor allem Arbeitslosenfürsorge, Arbeitsbeschaffung, Sozialversicherung, Heilkostenzuschüsse, Beschäftigungsbewilligung für Ausländer, die Sachaktenreihe (15 Bde, 1926-1940) Krankenkassenberichte, Bekämpfung des Alkoholismus, Tbc-Fürsorge, Blinden- und Taubstummenanstalt, Kriegsgräberfürsorge, Kriegsopfer und Versorgung mit Wohnungen.

- Kanzleistelle E: Allgemeine Aktenreihe (2 Bde) und Sachaktenreihe (21 Bde, 19381940) stammen aus den Fachgebieten: Allgemeine Schulangelegenheiten, Volksbildung, Schülerheime, schulärztlicher Dienst; Denkmalschutz, Bibliotheken, Museen und Archive, Landesgalerie, Kunst- und Musikverein. Die Kompetenzen wurden 1940 dem Landesschulrat übertragen.

- Kanzleistelle F : Die allgemeine Aktenreihe (47 Bde, 1940-1944) dokumentiert die Fachbereiche: Landwirtschaftsförderung, Meliorationen, Katastrophenbeihilfen; Wasserrecht und -bau; Elektrizitätsversorgung, Kraftwerks- und Leitungsbau; Straßenverkehr; Fluß- und Seeschiffahrt; Baupolizei. Sie setzt die entsprechenden Akten der 1939 aufgehobenen Kanzleistelle $\mathrm{G}$ fort.

- Kanzleistelle G: Allgemeine Akten (53 Bde, 1938-1939) stammen aus den 1939 auf die Kanzleistelle $G$ übergegangenen Sachgebieten und außerdem den später bei der Kanzleistelle B und der Sanitätsabteilung dokumentierten Kompetenzen für Sparkassen, Jagd und Fischerei, Landwirtschaftsschulen; Krankenanstalten, Apotheken, Ärztekammer, Sprengelärzte, Hebammen und Infektionskrankheiten. Die Sachaktenreihe (104 Bde, 1926-1939) enthält Unterlagen u. a. über Apotheken, amtsärztliche Berichte, Ärztekammer, Infektionskrankheiten, Krankenanstaltengesetz, Landeskrankenhäuser, Hebammen; Katastrophenschäden, Feuerversicherung, Landwirtschafts- und Hauswirtschaftsschulen; Wasserrecht, Wasserkraftanlagen; Sparkassen; Privatkrankenanstalten, Rauschgiftsüchtige, Krankenverpflegungskosten.

- Kanzleistelle J: In der allgemeinen Aktenreihe (180 Bde, 1938-1941) liegen die Schwerpunkte bei Fürsorgemaßnahmen (auch für Wehrmachtsangehörige), Fürsorgeerziehung und -verbänden, Familienunterhalt und Ehestandsdarlehen; Gemeindeangelegenheiten (Haushalt, Aufsicht, Eingemeindungen, Bedienstete, Gemeindetage, Straßen, 
produktive Arbeitsfürsorge); Fremdenverkehr (Statistik, Förderung, Beiträge, Landeskommission für Fremdenverkehr); Abschiebung von Ausländern und von mittellosen Inländern in ihre Heimatorte; Brückenbau und -erhaltung; Staatsbürgerschaft. Ab Mitte 1940 kamen das gesamte Personenstands- und Kultuswesen von Kanzleistelle B hinzu und als neuer Arbeitsbereich die Grenzlandfürsorge. Hauptbetreffe in der Sachaktenreihe (19 Bde) sind Gemeindetage, Gemeindesekretäre, Ehrenzeichen, Grenzlandfürsorge, Kärntner Golfklub, Landeshypothekenbank und Landesenergieabgabe.

- Sanitätsabteilung: Vorhanden sind (26 Bde, 1940-1944) Akten über Organisation des Gesundheitswesens, Haushalt und Gebühren - Bedienstete - Berufsvertretung der Ärzte; Zulassung und Sprengel - Apotheken - Drogen- und Arzneimittelverkauf Hebammen, Krankenpflegepersonal, Dentisten und Heilpraktiker - Wohnungs-, Wasserund Lebensmittelhygiene - Seuchen, Infektionskrankheiten, Impfungen - Luftschutz Verhütung erbkranken Nachwuchses, Eheberatung und Ehegenehmigung - Schulhygiene und Schulärzte.

Lit.: W. WADL, A. OGRIS: Das Jahr 1938 in Kärnten und seine Vorgeschichte. 1988.

\subsection{Reichsstatthalter in Niederdonau, Wien}

NÖLAW

Die Akten der Behörde des Landeshauptmanns von Niederösterreich und ab 1939 Reichsstatthalters in Niederdonau sind relativ gut überliefert (ca. 3000 Bde, 1938-1945); der Bestand wächst noch infolge laufender Aktenabgaben der entsprechenden Fachabteilungen der Landesregierung und enthält Schriftgut aus folgenden Sachgebieten:

- Dienst- und allgemeine Verwaltungsangelegenheiten: Korrespondenzen von Landeshauptmann Dr. Roman Jäger (März-Mai 1938) und Reichsstatthalter Gauleiter Dr. Hugo Jury (Mai 1938-April 1945) sowie einzelnen Mitgliedern der Landesregierung (1938/39); Personalangelegenheiten (Durchführung der Verordnung zur Neuordnung des Beamtentums, Entlassungen, Zwangspensionierungen, „politische Schadenswiedergutmachung“" Nachweis arischer Abstammung, dabei ca. 1800 Erhebungen über politische Zuverlässigkeit, politische und weltanschauliche Schulung); Lageberichte der Landräte (1940-März 1945) mit Angaben über Verhaftungen und Maßnahmen gegen Fremdarbeiter, Juden und Zigeuner (Ergänzungsüberlieferung für den Zeitraum 1938-1940 im Landratsamt Amstetten); Polizeiangelegenheiten (soweit nicht in den Wirkungsbereich der Sicherheitsdirektion fallend) mit ca. 2300 Vorgängen über Vereinsauflösungen und Einziehung staatsfeindlichen Vermögens, Maßnahmen gegen die Kirchen; Wahlen und Abstimmungen (u. a. Volksabstimmung vom 10. April 1938), Statistik und Reichsbürgerrecht (ca. 4000 Vorgänge über die Zuerkennung des Reichsbürgerrechtes); Rechtssachen (Ausgleich von Rechtsansprüchen der Reichsgaue Wien und Steiermark).

- Gemeindeangelegenheiten: Vermögensangelegenheiten, Kommunalaufsicht, Eingliederung der sudetendeutschen Kreise Neubistritz, Nikolsburg und Znaim (Personalmaßnahmen gegen Kommunalbeamte, Personalakten der Bürgermeister mit insgesamt ca. 400 politischen Beurteilungen, Rechtsangleichung, Verwaltungsaufbau, Vereinsauflösung, Einziehung staatsfeindlichen Vermögens); Freiwillige Feuerwehren und Feuerschutzpolizei (1938-1944, mit Runderlassen).

- Kultusangelegenheiten: Stiftungen und Fonds sowie Streubestände über Sammlungen zu kirchlichen Zwecken.

- Kulturelle Angelegenheiten (ca. 2000 Vorgänge): Volksbildung, Volksbüchereiwesen, Volksmusikpflege, Denkmalpflege sowie Angelegenheiten der wissenschaftlichen 
Forschung (Reichsgauarchiv Niederdonau, Bibliothekswesen, Landeskunde, Landesmuseum mit Außenstellen wie Museum Carnuntinum), Theater, Musikwesen, Rechtsangelegenheiten des Denkmal- und Naturschutzes.

- Finanzwesen: Haushalts-, Kassen- und Rechnungswesen der staatlichen Verwaltung, finanzielle Auseinandersetzungen mit den Reichsgauen Wien und Steiermark aufgrund der Gebietsveränderungen 1938.

- Handel und Gewerbe: Maßnahmen zur Preisbildung; Oberversicherungsamt; Errichtung der Gauwirtschaftskammern; Gewerbeförderung (mit ca. 400 politischen Beurteilungen); Schulaufsicht und Organisation des gewerblichen Berufsschulwesens (personalund dienstrechtliche Angelegenheiten, Entlassungen, Zwangspensionierungen); Aufsicht und Förderung des Fremdenverkehrs (nur Aktensplitter).

- Land- und Forstwirtschaft: Förderungsmaßnahmen, Höferecht, Jagdwesen, Veterinärangelegenheiten, Kreditwesen, landwirtschaftliche Lehranstalten (1938-1945), Meliorationen, Verbandswesen und Bewirtschaftung von landwirtschaftlichen Gütern, vor allem auch geschlossene Aktenserien über die „Anmeldung von Judenvermögen“ (Arisierungen, ca. 3500 Vorgänge), Beschlagnahme staatsfeindlichen Vermögens und die Entschuldung der Landwirtschaft (Landstelle Wien für ganz Niederösterreich).

- Gesundheitswesen und Soziales: Förderung der Rassenhygiene, Volkspflegeschulen (ca. 500 Personalakten und Standesblätter der Volkspflegerinnen); Maßnahmen gegen Asoziale und Fürsorgezwangsarbeit (ca. 300 Vorgänge); Erziehungsanstalten (Eggenburg, Znaim); Krankenanstalten mit Heil- und Pflegeanstalten Gugging und Mauer (Streubestände); Ehestandsdarlehen; Wohlfahrtsanstalten; Medizinalverwaltung (mit Personalvorgängen, 1938-1944, und Runderlassen).

- Angelegenheiten der Schulen und Kindergärten: Personalmaßnahmen der Landeslehrerkommission mit politischen Beurteilungen; Aufhebung konfessioneller Schulen und geistlich geführter Kindergärten; Beschlagnahme von Vereinsvermögen.

- Bauangelegenheiten, Wasserrecht und Energiewesen: Geschlossene Bestände aus den Sachgebieten Reichsautobahnen, Baupolizei, Dampfkesselwesen und Gaserzeugung, Straßen- und Brückenbau, Schiffahrt und Strombau, Vermessungswesen und Elektrizitätsversorgung, Agrartechnik.

Die Überlieferung der Gauselbstverwaltung enthält neben der Korrespondenz von Gauhauptmann Mayer vor allem Unterlagen über Personalmaßnahmen (Berufsbeamtengesetz), Einziehung von volks- und staatsfeindlichem Vermögen, Rechenschaftsberichte der Sachbearbeiter, Geschäftsberichte der Landeshypothekenanstalt sowie Berichte über die Prüfung der Gauanstalten. Andere Akten betreffen Uk-Stellungen, Arbeitsdienstverpflichtungen und den „Dr. Hugo-Jury-Plan“ (Wirtschaftsplan aus dem Jahre 1938 mit Vorschlägen für Innovationen und Angaben über vorbereitende Maßnahmen dafür).

Lit.: E. BEZEMEK: Zur NS-Machtübernahme in Niederösterreich. 1984/85. - M. SELIGER: NS-Herrschaft in Wien und Niederösterreich. 1988. - K.-D. MULLEY: Nationalsozialismus im politischen Bezirk Scheibbs 1930 bis 1945 . 1981.

\subsection{Reichsstatthalter in Oberdonau, Linz}

LZ, Best. C 45

Die Akten von Landesregierung/Landeshauptmann und Reichsstatthalterei des Reichsgaus, dessen Leitung dem Gauleiter August Eigruber übertragen war und zu dem außer Oberösterreich die sudetendeutschen Kreise Krummau und Kaplitz gehörten, sind vielfach vor 1938 angelegt und nach 1945 fortgeführt worden. Zum größten Teil wurden sie vor der Übernahme ins Archiv um 1965 mikroverfilmt und sind deshalb z. T. nur auf 
16-mm-Rollfilmen à $30 \mathrm{~m}$ (MF) überliefert, weil die Originale dann vernichtet wurden; alle noch vorhandenen Kanzleibehelfe (Register und Indices) wurden 1987/88 mikroverfilmt und 1992 ins Archiv übernommen. Soweit Originale archiviert sind, kann der Umfang nur in Schachteln (Sch., Höhe $13 \mathrm{~cm}$ ) angegeben werden. Der Bestand enthält aus den Jahren 1938/39 Schriftgut in folgender Gliederung:

- Kanzleiabteilung A: Präsidium, Personal, Kultur, Denkmalschutz, Kunst (1 Sch. und MF), Indices (MF).

- BA: Landesbauamt (1939, MF).

- Kanzleiabteilung C: Wohnungs- und Siedlungswesen, Sozialversicherung, Gewerbe, Verkehrsgewerbe (1 Sch. und MF), Indices (1936-1939, MF).

- Kanzleiabteilung D: Banken, Gemeinden, Land- und Forstwirtschaft, Militär, Staatsbürgerschaft, Wahlen, Verfassung, Kultus (27 Sch. und MF), GR = Gemeinderevisionen (MF), Indices (MF).

- Kanzleiabteilung E: Presse, Polizei, Verkehrsrecht, Naturschutz, Militär (2 Sch. und MF, u. a. „SD/Ver“: Vereinswesen), Indices (1935-1938, MF).

- Kanzleiabteilung F: Bau, Verkehr, Fürsorge (6 Sch. und MF), Indices (1936-1939, MF).

- Kanzleiabteilung G: Forste, Sanität, Stiftungen, Veterinärwesen, Wasser- u. Energierecht (9 Sch. und MF), Indices (1937-1939, MF).

Die von 1940 bis Kriegsende geführten Akten gliedern sich wie folgt:

- Ia: Innere Angelegenheiten (34 Sch. und MF), darunter Ia/Pol., Polizeiangelegenheiten ( 8 Sch. und MF), Ia/St., Personenstand, Matriken (10 Sch. und MF), Ia/B, Verwaltungsaufbau, -gebäude (1940, MF), Indices Ia/G (Gemeinden, 1940-1949 MF), Ia/Pol (1940-1945 MF), Ia/St (1940-1949 MF), Ia/Vet (1944-1949, MF).

- Ia/Pol, Prüfstelle für Filmvorführer (1941-1945, MF).

- Ib/P (ab 1942 Z/Pers): Personalangelegenheiten (MF), Indices (MF).

- IIa/G: Schulangelegenheiten (Aktenrest 1944-1945, MF).

- IId/N (1939 bis 30. 4. 1941 Naturschutzbeauftragter und Höhere Naturschutzstelle Oberdonau): Naturschutz (im Bestand C 12 a ca. 13 Sch., 1920-1953).

- IIIa/M: Sanitätswesen (8 Sch. und MF), Indices (1940-1945 MF).

- IIIb/FA: Fürsorgeaufsicht (16 Sch. und MF), Indices (1938-1945, MF).

- IVa/L und IVb/L: Landwirtschaft, Bodenrecht (MF, 1945), Indices IVa/L (19401946, MF).

- IVb/U: Umlegung (ca. 1 Sch. im Bestand C 11 a, Landesagrarsenat, 1912-1949).

- IVb/N: Bäuerliche Siedlung (6 Sch., vermischt mit Akten der Landesbauernschaft

Donauland (s. u. S. 255), Abt. I/F „Neubildung deutschen Bauerntums“, in Best. C 12 c).

- IVc/S (ab 1943 Gauwohnungskommissar in Oberdonau bzw. Wohn- und Siedlungsamt): Wohnungsbau und Siedlungswesen (ca. 30 Sch. 1945 fortgeführte Akten im Bestand C 34, Landesregierung: Wohnungswesen).

- IVc/V: Verkehr (3 Sch.), Indices (auch IVc/W, IVc/A, 1940-1949, MF).

- IVc/W (ab $1944 \mathrm{Ib} / \mathrm{Gew}$ ): Handel, Gewerbe, Industrie (8 Sch. bis 1943, MF bis 1945).

- IVc/W-Spar (1941-43 IVc/A-Sp, 1944 Ib/B/Sp) und Sp/Reg (Sparkassenregister): Sparkassenwesen (7 Sch. und MF).

- IVc/W 4 (1944 Ib/J): Sonderdezernat „Entjudung“ (mit Ausnahme des landwirtschaftlichen Grundbesitzes, 36 Sch. mit ca. 400-500 Einzelfällen im Bestand C 32 
„Arisierungen“, ferner zahlreiche, großenteils nach 1945 zu Rückstellungszwecken weitergeführte Akten in den Beständen: „BV-VR“ (s. u. Landesfinanzamt, S. 235), „FIRK“ (Abteilung Vermögenssicherung/Finanzabteilung des Amtes der oö. Landesregierung, 11 Sch., Bestand C 39) und „Gauselbstverwaltung“ (ca. 9 Sch., Verzeichnissignatur B 9), Indices (Arisierungsakten 1939-1945, MF).

- IVd: Preisbildung u. -überwachung (68 Sch. im Bestand C 20, „Preisbestimmung und Preisüberwachung“), Indices (1938-1945, MF).

- V: Bauwesen (Indices, 1940-1945, 45 MF).

- Va/H1: Hochbau 1 (19 Sch. im Bestand C 10 c, Reichsbauamt Linz, Pläne für Technische Universität Linz/Wilhering in der Karten- u. Plänesammlung).

- Va: Hochbau (1 Sch. und MF bis 1942), Indices (1940, MF).

- Vb: Straßenwesen (16 Sch. und MF).

- Vd/M: Kraftfahrzeuge, -lenker (MF, 1945).

- Ve: Bau- u. Wasserrecht, Baupolizei (11 Sch. und MF).

- OV/V: Oberversicherungsamt (1 Sch. und MF, 1945), Indices (1942-1944 MF). Aus der Gauselbstverwaltung stammen Akten der Kanzleiabteilungen I vor allem über Schulwesen (ca. 40 Bde, T, darunter Akten des Landesschulrates, 1938-1940) und Kinderlandverschickung (1939-1945) und III, vor allem in Finanzangelegenheiten und über Landesgüterverwaltung (ca. 30 Bde, auch betr. Enteignungen, 1940, im Best. GK/H, GK/V), wenige (bis Sommer 1938) aus den Kanzleiabteilungen II, IV und V über Gemeindeangelegenheiten, Gesundheitswesen und Straßen- u. Brückenbau. Ab 1939/40 wurden ihre Aufgaben personell von Abteilungen der Reichsstatthalterei wahrgenommen und sind in deren Akten über Kultur- und Gemeinschaftspflege (IId), Gesundheitswesen und Leibesübungen (IIIa), aus dem Gaufürsorgeamt (IIIb) und über Wirtschaftsförderung (IV) und Straßenbau (Vb) dokumentiert. Eine Ausnahme bildet die Überlieferung der Gaukämmerei, die hauptsächlich die Vermögensverwaltung betrifft (ca. 30 Sch., 1940-1944, der Aktengruppe GK/V im Bestand B 9), die sich vielfach mit entsprechenden Akten der Reichsstatthalterei (IVc/W4: Sonderdezernat Entjudung) und des Landesfinanzamtes überschneidet.

Lit.: H. SLAPNICA: Oberösterreich - als es Oberdonau hieB. 1978. - B. KEPPLINGER: Aspekte nationalsozialistischer Herrschaft in Oberösterreich. 1988.

\subsection{Reichsstatthalter in Salzburg}

Die wichtigste Überlieferung für die Zeit von 1938 bis 1940 befindet sich in den Aktenserien des Präsidialbüros (120 Kts) von Landeshauptmann und Gauleiter Friedrich Rainer, der als Reichsstatthalter 1941 durch Gauleiter Gustav Scheel ersetzt wurde. Sie betreffen u. a. Verleihung von Auszeichnungen, Verwaltungsorganisation (dabei Nutzung beschlagnahmter kirchlicher Gebäude durch Verwaltung und NSDAP, Entlassung und Ernennung von Beamten und Bürgermeistern), Maßnahmen gegen Juden, Luftschutz, Fremdenverkehr, Verhinderung der Landflucht, Polizei- und Gendarmerieorganisation, Personenstandswesen (Ein- und Ausbürgerung, Aufenthaltsverbote, Ehesachen), Vereine und Verbände, Theater und Film, Einführung von Reichsrecht, Reichsverteidigungsangelegenheiten (Uk-Stellungen), Statistik (u. a. Volks- und Viehzählungen), Straßenverkehr, gewerbliche Wirtschaft, Naturschutz, Berufung in Verwaltungsstrafsachen; relativ umfangreich sind die Akten über Wasserkraftwerke, -leitungen und -schutzbauten, über Reichsbahn und Reichspost, politische Lageberichte sind dagegen nur von einzelnen Landräten vorhanden. Ersatzüberlieferung können die gut erhaltenen Akten der Be- 
zirkshauptmannschaften bzw. Landratsämter Salzburg Land (107 Kts, 1938-1945), St. Johann (174 Kts, 1938-1945) und Zell am See (183 Kts, 1938-1945) bieten.

Vorhanden sind ferner Registraturhilfsmittel (4 Bde, 1938-1945), Geschäftsverteilungs- und Organisationspläne (3 Bde, 1939-1941), allgemeine Anweisungen (6 Bde, 1940-1945) und von folgenden Organisationseinheiten Sachakten:

- Büro des Landeshauptmanns (37 Bde, 1939-1940), vor allem Grundstücksangelegenheiten mit Beschlagnahme von Kirchenbesitz, auch Dispositionsfonds 1939, Sichtung von Klosterbüchereien durch das Gauschulungsamt.

- Büro des Reichsstatthalters (133 Bde, 1940-1945), u. a. Arisierungen (13 Bde, u. a. zugunsten von Reichsminister Rust), Ankauf von Kunstwerken (9 Bde), Beschlagnahme und Ankauf von - z. T. kirchlichen - Liegenschaften (8 Bde, u. a. für HJ, Bildhauer Thorak, Göring, Reichsleiter Buch, Schlösser Fuschl und Kleßheim), Programm für Einführung Scheels durch Frick (1941), Strafverfahren gegen eine Schieberbande (1942), Forst- und Jagdsachen (6 Bde), Fremdenverkehr.

- Abteilung I, Allgemeine und innere Angelegenheiten:

- - Geschäftsverteilung (1940), Verordnungs- und Amtsblatt (1940-1941).

- Polizei (599 Bde), u. a. Ministerialerlasse (1945), Verleihung von Orden und Auszeichnungen, insbesondere Ehrenkreuz der deutschen Mutter (24 Bde, 1941-1945), Polizeiwohnungen (13 Bde, 1940-1943), Maßnahmen gegen Zigeuner (8 Bde, dabei Zigeunerlager Leopoldskron, Beschäftigung für Filmaufnahmen von Leni Riefenstahl 1941-1943), Volkstumsangelegenheiten (4 Bde, dabei „Volkspolitischer Rundbrief für den Gau Salzburg“, Februar 1945), Personalangelegenheiten (363 Einzelfälle mit Entlassungen und Maßregelungen aus politischen Gründen, einzelne leitende Beamte der Gestapo), Dienstgebäude und Kasernen (26 Bde), Maßnahmen gegen Asoziale (3 Bde, u. a. Unterbringung in Arbeitserziehungslagern), Kriegsgefangene und Fremdarbeiter (25 Bde), sonstige Ausländerpolizei (14 Bde), Feuerwehr und Luftschutz (51 Bde), Grenzangelegenheiten (3 Bde).

- Vereinswesen, Verkehr und Fremdenverkehr (345 Bde), u. a. Vorgänge über einzelne Versicherungs-, Sport-, Verkehrs-, Schützen-, Spar-, kirchliche, Musik- und Tierzuchtvereine (insgesamt 191 Bde, dabei Antisemitenbund, Katholischer Universitätsverein, NS-Turn- und Sportgemeinde), Straßen-, Schienen- und Luftverkehr (76 Bde, dabei Befehle des Korpsführers des NSKK über Beförderungen 1942-1943, außerdem 20 Bde über Fahrschulen), Fremdenverkehr (35 Bde, dabei Landesfremdenverkehrsverband Oberdonau und Salzburg, Kinderlandverschickung, Statistiken).

- - Verhältnis Kirchen und Staat (18 Bde), u. a. Kirchenvermögen vor allem der katholischen Kirche (8 Bde), Angelegenheiten der Evangelischen Kirche (6 Bde) und der Altkatholiken (2 Bde).

- - Justizsachen im allgemeinen (20 Bde, dabei Kompetenzabgrenzung zu Gauselbstverwaltung und Polizeibehörden), Judensachen (4 Bde Allgemeines, 8 Einzelfälle), einzelne Beschwerden und Rechtsstreitigkeiten (50 Bde, u. a. mit Gauverlag der NSDAP, politische Strafsachen, Beschwerde von Helene Thimig-Reinhardt gegen Enteignung von Schloß Leopoldskron, Einsprüche gegen Entlassungen aus dem öffentlichen Dienst).

- - Angelegenheiten von Stiftungen und Fonds (21 Bde), dabei eine jüdische und fünf kirchliche, Stiftung Schloß Fuschl des Reichsaußenministers v. Ribbentrop.

- Unterabteilung IV d, Preisbildungs- und Preisüberwachungsstelle (1296 Bde): u. a. Devisenstrafsachen, Bekämpfung des Schleichhandels, Arisierung von Grundstücken, Berichte zur Versorgungslage und über Strafen gegen Preisverstöße, „Preispolitische 
Nachrichten“ (1944), „Vertrauliche Monatsberichte“ des Reichskommissars für die Preisbildung (1943), vor allem Festsetzung der Preise für Fleisch, Obst und Gemüse, Textilien, elektrische Energie, in der Bauwirtschaft und im Beherbergungsgewerbe (Stadt Salzburg und Badgastein), von Mieten, Löhnen (u. a. für Kriegsgefangene, Arbeitsbedingungen der Front-OT) und Gebühren (u. a. für freie Berufe und Sippenforscher), der Pflegesätze für Geisteskranke, außerdem Akten betr. Übernahme des „Salzburger Volksblatts" durch den Gauverlag der NSDAP (1943), Umbau von Schloß Kleßheim (1944), Tauernwerk Kaprun, Anordnungen des Viehwirtschaftsverbandes Alpenland (1944).

- Abteilung V, Bauwesen:

- - Allgemeine technische Angelegenheiten (303 Bde, davon 162 Einzelfälle): u. a. allgemeine Personalsachen, Bewirtschaftung, Einsatz von Fremdarbeitern, Zuteilung von Baustoffen, aber auch Niederschriften über Abteilungsleiterbesprechungen bei Scheel (April 1942-Januar 1943), Dienst- und Geschäftsanweisungen des Reichsstatthalters (1940-1945), Vortrag des Staatssekretärs Stuckart „Das allgemeine Verhältnis von Reichsstatthalter, Regierungspräsident und Gauhauptmann in den Reichsgauen der Ostmark" (1940).

- - Rechtsangelegenheiten (215 Bde), insbesondere Einzelfälle der Baupolizei (123 Bde), Privatgleisanschlüsse und andere Eisenbahnsachen (49 Bde), Straßenbausachen (34 Bde).

- - Wasser- und Energiewirtschaft (154 Bde), überwiegend Einzelfälle, u. a. Wasserversorgung der Kampfstätte der nationalsozialistischen Bewegung in Lamprechtshausen, des Reichslehrhofes Alpenland der HJ in Scheffau und von RAD-Lagern, auch Energiewirtschaftsplanung (1940-1941).

- - Reichsbauverwaltung - Hochbau (111 Bde, dabei Beschwerde der Wirtschaftsgruppe Bauindustrie über Bevorzugung von Firmen aus dem Altreich, Unterbringung des Sven Hedin-Instituts für Ostasienforschung in Schloß Mittersill, Nutzung beschlagnahmter kirchlicher u. a. Gebäude) und - Straßen- und Brückenbau (108 Bde).

- - Maschinenbau und Elektrotechnik (42 Bde), u. a. Rad- und Motorradrennen, Hochspannungsleitungen, Seilschwebebahnen.

- - Wasserwirtschaft (125 Bde), vor allem Regulierung der Salzach und andere Wasserbaumaßnahmen, dabei auch Reichswasserwirtschaftstag 1939 in Bad Ischl und Linz, Tauernkraftwerk Kaprun (1940-1941), Nationalpark Hohe Tauern, Lagervorschriften des Arbeitserziehungslagers Ibern-Waidmoos bei St. Pantaleon (1940).

- Gaukämmerei (364 Bde): Allgemeines, Organisation der Gauselbstverwaltung (mit Geschäftsverteilungs- und Aktenplan), Diensttagebücher (1942-1944), persönliche Korrespondenz von Gaukämmerer Dr. Robert Lippert (1944); Aufwendungen für Sportveranstaltungen, Heime und Fürsorgeeinrichtungen, Schulen, Raumordnung, Künstler und kulturelle Einrichtungen (Theater, Mozarteum, Salzburger Festspiele, Galerien, 19 Bde, 1924-1940), Verkehr, Fremdenverkehr, Bergbau, Landwirtschaft (Landesgüter), Heilanstalten; Beschlagnahme von Klöstern, Bibliotheken und Kunstgegenständen; Arisierungen (14 Einzelfälle, 1939-1941); Errichtung des Gausippenamtes; Dispositionsfonds des Gauleiters (1939-1941).

Eine Ergänzungsüberlieferung bieten die Akten des Verfahrens gegen Scheel vor dem Landesgericht Linz als Volksgericht 1948 (20 Kopien DÖW), die Repressionsmaßnahmen gegenüber der katholischen Kirche und ihren Einrichtungen sind im Konsistorialarchiv Salzburg dokumentiert.

Lit.: E. HANISCH: Nationalsozialistische Herrschaft in der Provinz. 1983. - ders.: Die Errichtung des Reichsgaues Salzburg 1939/40. 1981. 


\subsection{Reichsstatthalter in der Steiermark, Graz}

GR

Der Anteil der Akten der Behörde des Reichsstatthalters und Gauleiters Sigfrid Uiberreither, die bis 1940 als Landeshauptmannschaft und Landesstatthalterei firmierte, ist in der Gesamtüberlieferung der Steiermärkischen Landesregierung nur gering. Sie verteilt sich vor allem folgendermaßen auf die einzelnen Gruppen des Kanzleiplans, wobei die Zahl der Faszikel angegeben ist, die jeweils durchschnittlich 20 Aktenhefte enthalten:

- Verfassung und Nationalpolitik (436, davon 352 betr. Staatsangehörigkeitsangelegenheiten, 54 betr. volkspolitische Betreuung der sechs Grenzlandkreise).

- Reichs- und Gaufinanzen (88, davon 34 betr. Verwaltung der Dienstgebäude).

- Kreis- und Gemeindeangelegenheiten (52).

- Personalangelegenheiten (870).

- Personenstandssachen einschl. Adoptionen und Eherecht (155).

- Armenfürsorge (18).

- Gesundheitswesen (23, daneben noch 41 aus dem Landesgesundheitsamt).

- Arbeit und Soziales (22).

- Veterinärwesen (8).

- Bergbau- und Hüttenwesen (6).

- Elektrizitätswirtschaft (38).

- Straßen- und Schienenverkehr (39).

- Bausachen (13).

- Wasserrechtsangelegenheiten (64).

- Handel, Gewerbe und Industrie (25).

- Kirchliche Angelegenheiten (14).

- Bildungswesen, kulturelle Angelegenheiten (24).

- Polizei, insbes. Verwaltungspolizei (53, davon 20 betr. Vereine bis 1942).

- Technik (143 vom Technischen Landesamt, dabei 79 betr. Straßenbau).

Ergänzungsüberlieferung enthält der Nachlaß des Leiters der Schul- und Wissenschaftsabteilung Landesrat Josef Papesch, über die Beschlagnahme von kirchlichem und jüdischem Eigentum gibt es Vorgänge in Akten des Landesmuseums Johanneum.

Lit: Ämter-Führer von Graz und Steiermark. 1939/40 (mit Positionen des Kanzleiplans). - G. GÄNSER: Kontinuität und Bruch in der steirischen Landesverwaltung. 1988. - S. KARNER: Die Steiermark im Dritten Reich 1938-1945. 1986. - L. MIKOLETZKY: Josef Bürckels Dienststelle und die Steiermark 1938/39. 1981.

\subsection{Reichsstatthalter in Tirol und Vorarlberg, Innsbruck IN}

Unter Landeshauptmann und dann Reichsstatthalter und Gauleiter Franz Hofer, der Ende Mai 1938 an die Stelle von Edmund Christoph getreten war, wurden die Bundesländer Tirol und Vorarlberg (bis dahin unter Landeshauptmann Anton Plankensteiner) im April 1939 zu einem Reichsgau vereinigt, jedoch war der Osttiroler Bezirk Lienz Kärnten zugeschlagen worden. Das Schriftgut der Landeshauptmannschaft von Tirol ist wie folgt überliefert:

- Präsidialabteilung: Organisation, Personalwesen, Wahlen, Polizei, Gendarmerie, Militär, Schützenwesen, Berg Isel, Allgemeines (38 Bde, 1938-1945, inklusive Akten aus der Zentralabteilung des Reichsstatthalters).

- Abteilung Ia: Gewerbe-, Verkehrs- und Vereinsangelegenheiten (14 Bde, 1938-1940).

- Abteilung IIa: Staatsbürgerschaft, Heimatrecht, Krankenanstalten, Hochschulangelegenheiten (5 Bde, 1938-1940).

- Abteilung IIb: Gesundheitswesen (5 Bde, 1938-1939). 
- Abteilung III: Kultus, Ehe, Kunst, Stiftungen, Stipendien, Personenstandsangelegenheiten, Landw. Landesschulen, Landesanstalten, Wohnungswesen, Volkszählung, Denkmalschutz (16 Bde, 1938-1939).

- Abteilung Va: Naturdenkmäler und Heimatschutz, Straßenangelegenheiten und -polizei, Wasserrecht, Jagd, Forstpolizei usw. (16 Bde, 1938-1940).

- Abteilung Vc: Veterinärwesen (6 Bde).

- Bauamt: Wasserbau, Straßenbau, Hochbau, Kulturtechnischer Dienst (39 Bde, 19381940).

Nur Reste sind vorhanden von den Akten der Abteilungen VI (Gemeindeangelegenheiten, Armen- und Unterstützungswesen, Feuerpolizei, Wirtschaftsangelegenheiten) und VII: Kredit- und Finanzwesen, Landeshaushalt, nicht vertreten sind die Abteilungen Ib (Versicherungsangelegenheiten, soziale Fürsorge), Ic (Kurwesen, Fremdenverkehr), IV (Bodenreform, Grundbuchanlegung), Vb (Forsttechnischer Dienst), IXa und $\mathrm{b}$ (Landes- und Bundesrechnungsdienst, Landesbuchhaltung und -kasse).

Folgende Akten der Landeshauptmannschaft Vorarlberg befinden sich im Landesarchiv in Bregenz:

- Landeshauptmann (4 Sch., 1938-1940).

- Präsidium: Innerer Dienst, Organisation, Landtag, Reichsverteidigung, Gesetzgebung, Polizei, Statistik (8 Sch., 1938-1939).

- Abteilung Ia: Wirtschaft, Soziales, Vereins- und Versammlungswesen, Verkehr, Presse, Justiz (u. a. Devisenstrafsachen), Ernährung, Zölle, Paß- und Auswanderungsangelegenheiten (35 Sch., 1938-1939).

- Abteilung Ib: Personenstandswesen, Kultus und Unterricht, Ausländerpolizei, Maßnahmen gegen Zigeuner (8 Sch., 1938, Nachakten bei Abteilung II).

- Abteilung II: Kommunalangelegenheiten, Sozialfürsorge, Feuerpolizei, Straßenverkehrsrecht, Landeskultur, Fremdenverkehr, Jugendpflege, Theater und Film, Sammlungsrecht, Soziales (ab 1939), Siedlungswesen (43 Sch., 1938-1939).

- Abteilung IIa: Militärangelegenheiten, Verkehr, Kommunalangelegenheiten (4 Sch. ab Juli 1939).

- Abteilung III a: Gesundheitsdienst (6 Sch., 1938-1939).

- Abteilung III b: Veterinärwesen (11 Sch., 1938-1939).

- Abteilung IV (Gaukämmerei): Landesfinanzen (44 Sch., 1939-1945).

- Abteilung V: Bauverwaltung (47 Sch., 1938-1939, ferner 11 Bde des Wasserwirtschaftsamtes).

- Abteilung VII (Landesstelle für Raumordnung und Landesplanung, 20 Bde, 1938-1940).

Aus der Reichsstatthalterei für Tirol und Vorarlberg stammen folgende Akten:

- Abteilung I (Allgemeine und innere Verwaltung): Hoheitsangelegenheiten (2 Bde, 1940-1944); Gemeindeaufsicht (3 Bde, 1941); Gemeindeprüfung (3 Bde, 1942-1945); Reichsverteidigung (11 Bde, 1938-1945); Polizei- und Verkehrswesen (2 Bde, 19401943); Staatsangehörigkeit, Rasseschutz, Personenstands- und kirchliche Angelegenheiten (26 Bde, 1940-1944); Veterinärangelegenheiten (10 Bde, 1941-1945); Schutzpolizei und Grenzaufgaben (1 Bd, 1939-1944); Naturschutz (1 Bd, 1940-1944).

- Abteilung II (Schule, Erziehung und Kultur): Hauptschulen (2 Bde, 1940-1941); Volksschulen (1 Bd, 1940-1941); Landwirtschaftliche Berufsschulen (2 Bde, 19421945).

- Abteilung III (Gesundheitswesen und Fürsorge): Medizinalangelegenheiten (24 Bde, 1940-1944). 
- Abteilung IV (Landwirtschaft, Wirtschaft und Arbeit): Landwirtschaft (9 Bde, 19401945); Wirtschaft (18 Bde, 1941-1945); Wohnungs-, Siedlungswesen (10 Bde, 19401945); Preisbildung und -überwachung (10 Bde, 1938-1944); Lebensmittelversorgung (Abteilung B des Landesernährungsamtes Salzburg, 5 Bde, 1939-1945); Entschuldung (4 Bde der Landesstelle Innsbruck für Bauernentschuldung, 1939-1945, und 201 Bde anderer Landesstellen sowie der Tiroler Landesregierung, 1946-1966).

- Abteilung V (Bauwesen): Straßenbau (19 Bde, 1940-1945); Wasserwirtschaft (11 Bde, 1940-1945); Hochbau (33 Bde, 1939-1945); Verwaltung und Recht (16 Bde, 19401945).

Akten der für die allgemeine Verwaltung von Vorarlberg zuständigen Abteilung VI mit Sitz in Bregenz befinden sich im dortigen Landesarchiv (78 Sch., 1940-1941).

Aus der Gauselbstverwaltung sind nur Aktenreste des Gauhauptmanns Linert (7 Bde, 1939-1945) und aus der Gaukämmerei (11 Bde, 1940-1945) überliefert.

Ergänzungsüberlieferung liegt in den Akten des Verfahrens des Landesgerichts Innsbruck als Volksgericht gegen Hofer vor (30 Kopien daraus im DÖW).

Lit.: W. BEIMROHR: Staat und Partei des Dritten Reiches in Tirol. 1988. - H. SCHREIBER: Vom AnschluB zum Krieg. Tirol 1938/39. 1991. - E. HANISCH: Westösterreich. 1988.

\subsection{Reichsstatthalter im Sudetenland, Reichenberg}

Der 1938 errichtete Reichsgau umfaßte die von Deutschen bewohnten Teile Böhmens, Mährens und des bis 1918 österreichischen Schlesiens, zu deren Abtretung die Tschechoslowakei im Münchener Abkommen gezwungen worden war, mit Ausnahme der zu Bayern (vgl. Bd. 1 S. 105, 107), Ober- und Niederdonau (vgl. oben S. \#) geschlagenen Kreise. Reichsstatthalter wurde der bisherige Führer der Sudetendeutschen Partei und Gauleiter der NSDAP Konrad Henlein. Zum überlieferten Bestand (1035 Amtsbücher, 1112 Kts Akten im Gesamtumfang von 149,5 lfm) gehört aus seiner Kanzlei (11 Kts) ein Teil seiner Korrespondenz, jedoch nur mit Partnern mit Anfangsbuchstaben E-N, R-S (dabei auch NSDAP).

Zentrale Verwaltungsangelegenheiten (1938-1945) sind in Akten aus dem Hauptbüro dokumentiert. Sie betreffen Aufbau, Geschäftsbereich und Organisation der Behörde (7 Kts), Personalangelegenheiten der Beamten und Angestellten, Haushalts- und Rechnungswesen (4 Kts) sowie Liegenschaften (4 Kts), ferner den Reichshaushalt (11 Kts). Damit vereinigt wurden Aktensplitter des Inspekteurs der Ordnungspolizei (1 Karton).

Aus der I. Abteilung für allgemeine, innere und kulturelle Angelegenheiten sind zu folgenden Betreffen Archivalien vorhanden:

- Zivile Reichsverteidigung: Akten des Reichsverteidigungskommissars (9 Kts, 1940-1945, Ia RV), u. a. mit Monatsberichten über Lage der Wirtschaft.

- Kommunalverwaltung: Organisation, Personalangelegenheiten, Finanzzuweisungen, Steuern (90 Kts, 1938-1945, Ia Kom).

- Feuerschutzpolizei (2 Kts, Ia Pol).

- Gesundheitswesen, Ärzte, Apotheken, Arzneimittel (79 Kts, Ia Med), u. a. Behandlung erkrankter Ostarbeiter, Abtreibungen bei Fremdarbeiterinnen.

- Archivwesen: Aufsicht über die Reichsarchive Reichenberg und Troppau (Ia StA).

- Öffentliche Fürsorge (5 Kts, 1939-1945, Ia Fürs).

- Personalangelegenheiten der Lehrer, der Wissenschaftsverwaltung, Kirchen, der Wirtschafts-, Bau- und Forstverwaltung, Ansiedlung und Umsiedlung von Deutschen in den böhmischen und mährisch-schlesischen Grenzgebieten (200 Kts, Ib). 
- Erziehung und Volksbildung (127 Kts, 1938-1945, Ic), u. a. über Kinderlandverschickung.

Aus der II. Abteilung für Wirtschaft, Landwirtschaft und Arbeit stammen nur wenige Akten aus den Kompetenzen für Wirtschaft und Arbeit (5 Kts, 1938-1945, IIa) und der Preisbildungsstelle (6 Kts, 1938-1945, IIc).

Einen beträchtlichen Teil des Bestandes bildet Schriftgut der III. Abteilung für Siedlung und Umlegung über Neubildung deutschen Bauerntums und Umsiedlung deutscher Bauern zur Germanisierung der abgetrennten tschechischen Grenzgebiete, ferner über Arisierung landwirtschaftlichen Grundbesitzes (insgesamt $123 \mathrm{Kts}$, IIIa LK) und aus der Domänenverwaltung (18 Kts, 1938-1945, IIIb, IIb) u. a. über die Übernahme tschechischer Liegenschaften in Reichsbesitz.

Die erhaltenen Akten der IV. Abteilung für Bauwesen betreffen Hochbau (136 Kts, IVa), Straßenbau (100 Kts, IVb), dabei Planung der Reichsautobahn im Grenzgebiet, und Wasserwirtschaft (1 Karton, IVc).

Einen Teilbestand (insgesamt 481 Amtsbücher, 1246 Aktenbde, $137 \mathrm{Kts}, 11 \mathrm{Karteien}$, 1938-1945) bildet das Schriftgut der Gauselbstverwaltung unter (bis Herbst 1943) Gauhauptmann Dr. Anton Kreißl. Von ihm stammen Präsidialakten (11 Bde) und persönliche Korrespondenz (9 Bde) mit NSDAP, SS und weiteren Gliederungen und ihren Repräsentanten, darunter Regierungspräsident Hans Krebs.

Bei den Amtsbüchern handelt es sich vor allem um Haushaltsrechnungen und andere Unterlagen der Hauptkasse der Gaukämmerei (308 Bde) und um Journale und andere Registraturhilfsmittel auch nachgeordneter Anstalten und Einrichtungen, ferner 2 Verzeichnisse der Angestellten und Abrechnungen der Versorgungskasse mit Listen von Hinterbliebenen, Versicherten und Rentnern (1941-1945).

Die Akten sind in 10 Hauptgruppen geordnet, jedoch fehlt die Überlieferung aus den Gruppen 5 (Jugendwohlfahrt) und 8 (Wirtschaftsbetriebe):

0 - Personalangelegenheiten der Gauselbstverwaltung (407 Bde).

1 - Verwaltung (186 Bde), u. a. Aufgaben und Verfassung der Gauselbstverwaltung (2 Bde), Hoheitsangelegenheiten (1 Bd), Präsidialangelegenheiten (2 Bde), Revisionen (101 Bde).

2 - Versicherungsangelegenheiten, Rentenkasse (106 Bde).

3 - Kulturelle Angelegenheiten (164 Bde).

4 - Sozialfürsorge: Fürsorge- (24 Bde) und Heil- und Pflegeanstalten (92 Bde).

6 - Bauangelegenheiten (57 Bde).

7 - Wirtschaft (71 Bde), u. a. Grundstückverkehr, Zuteilung von Bauernhöfen, Fremdenverkehr, Förderung der Landwirtschaft.

9 - Finanzverwaltung und Kasse (81 Bde).

Außerdem vorhanden sind in großer Zahl Personalakten der Angestellten der Gauselbstverwaltung und zugehörige Karteien auch von Witwen und Pensionären; eine weitere Kartei weist Grundbesitz nach. Ferner befinden sich im Bestand Akten der Landesversicherungsanstalt (12 Kts), der Verpflegungskasse (9 Kts) und der Hauptkasse (8 $\mathrm{Kts})$.

Akten über Gleichschaltung oder Auflösung von Vereinen und Organisationen im Sudetenland sind in der Überlieferung des Stillhaltekommissars für Vereine, Organisationen und Verbände in Österreich enthalten, der eine Zweigstelle in Reichenberg einrichtete (vgl. oben \#\#); dazu gehört reichhaltiges Material über die Konsumgenossenschaften. 


\subsection{Reichsstatthalter in Danzig-Westpreußen, Danzig}

DAN, Best. 236/I, BA KO, Best. R 138 I

Der Danziger Bestand (24 Bde, 1939-1945) enthält nur Aktensplitter betr. inneren Dienst (3 Bde, 1939-1944), Schriftverkehr (3 Bde, 1941-1945), Ortsnamenänderungen (12 Bde, 1939-1943), Ausgabeordnung für Wertpapiere (2 Bde, 1939-1945), Wasserversorgung (1 Bd, 1944), Feststellung der Volkstumszugehörigkeit in Westpreußen (1944), Organisation der Reichsstatthalterei (1940) sowie Runderlasse des Reichsinnenministeriums (1943).

Weitere Aktensplitter sind als Nachakten des Oberpräsidiums von Westpreußen bzw. des Danziger Senats überliefert (98 Bde, 1933-1942, im Best. 7/I). Sie betreffen die Verpachtung der Marienburg (5 Bde, 1924-1940), die Landratsämter Elbing, Marienburg, Marienwerder, Rosenberg und Stuhm (5 Bde, 1920-1938), Bauten des Wasserbauamtes Marienburg (6 Bde, 1921-1939), Haushaltsangelegenheiten (12 Bde, 1929-1940), die Grenze zwischen Reich bzw. Preußen und der Freien Stadt Danzig (4 Bde, 1933-1940), Jagdnutzung (1884-1935), Kultur und Kunst (1 Bd, 1897-1937), Beamte und Angestellte (6 Bde, 1933-1940), Schiffahrt, Brücken, Hochwasser, Häfen und Leuchtfeuer der Weichsel (29 Bde, 1914-1942) und den Kanal zur Nogat (14 Bde, 1925-1940).

Der Koblenzer Teilbestand enthält neben einzelnen Berichten über Stimmung und Lage der Polen (1939-1941, 1945), Erlassen und Rundschreiben (1941) vor allem Akten der Unterabteilung IV B, Siedlung und Umlegung (111 Bde), u. a. über Dienststellenverwaltung, Organisation und inneren Dienst (21 Bde, 1939-1944, dabei Zusammenarbeit mit der NSDAP), Personalangelegenheiten (7 Bde, 1939-1944), Planung und Finanzierung (15 Bde, 1939-1945), Bauten, insbesondere Wiederaufbau zerstörter Bauernhöfe (13 Bde, 1939-1944), Landvorrat und -bedarf für die Ansiedlung von Deutschen mit Generalsiedlungsplan (43 Bde, 1939-1944). Weitere Restakten stammen vom Bevollmächtigten für den Nahverkehr (7 Bde, 1940-1944, betr. Aufsicht über Straßenbahnen) und aus der Gaukämmerei (Haushalt der Gauselbstverwaltung, 4 Bde, 1940-1941, 1944).

Ersatzüberlieferung liegt in den Akten aus dem Prozeß gegen Gauleiter und Reichsstatthalter Albert Forster vor dem Obersten Volksgericht der VR Polen vor (GKW) und in 383 Berichten von Persönlichkeiten des öffentlichen Lebens (BA KO, Ost-Dok. 8), darunter der Adjutant Forsters, die Leiter der Abteilung Erziehung und Unterricht und des Gaujugendamtes, der Gaukämmerer und der Generalreferent für Raumordnung; ein Rechenschaftsbericht des Gaukämmerers gehört mit weiteren vor allem über die Wasserwirtschafts-, Landwirtschafts- und Forstverwaltung zu den „Berichten über die Tätigkeit der deutschen Verwaltung (Ost-Dok. 13).

Lit.: GRUNDRISS zur deutschen Verwaltungsgeschichte 1815-1945. Reihe A, Bd. 1: Ost- und Westpreußen. 1975. - Z. JANOWICZ: Ustroj administracyjny ziem polskich wcielonych do Rzeszy Niemieckiej 1939-1945. Tzw. Okregi Kraju Warty i Gdanska-Prus Zachodnych. 1951.

\subsection{Reichsstatthalter im Wartheland, Posen}

POS, Best. 299; GKW Best. 62

Der Hauptteil der Überlieferung (3237 Bde, 1939-1945) befindet sich in Posen, ein kleiner Teil (375 Bde, 1933-1945) in Warschau, wo auch die Akten aus den Verfahren gegen Gauleiter und Reichsstatthalter Arthur Greiser (Mikrofilm des Protokolls seiner Vernehmung durch US-Behörden aus den National Archives Washington im BA P, Film 72588) und seinen Vertreter, Regierungspräsident August Jäger (ein Teilnachlaß in POS), aufbewahrt werden. Die Akten stammen aus folgenden Abteilungen: 
Abteilung I, Allgemeine, innere und finanzielle Angelegenheiten (1857 Bde):

- Allgemeines (18 Bde) und Geschäftsführung (11 Bde, 1940-1944): Verordnungen, Runderlasse und -schreiben des Reichsstatthalters (12 Bde, 1939-1944). - Konferenzen, Referenten- u. a. Besprechungen, Lageberichte, Besichtigungsreisen (u. a. mit Reichsinnenminister Frick, 18 Bde, 1940-1945), Schriftverkehr in Personalsachen, Abordnung und Versetzung polnisch versippter Beamter, Lageberichte, Deutscher Volkssturm, Transportschwierigkeiten. Sammlungen von Anordnungen und Berichten des Reichsstatthalters (17 Bde, 1939-1944) befinden sich auch im Warschauer Bestand.

- Dienststellenverwaltung (48 Bde, 1939-1944), u. a. Beamtendienstangelegenheiten, Heranziehung zum Flakdienst, Luftschutz- und Brandwache, Aufsicht über Landräte, Dienstreisen, Stadtwacht, Leistungskampf, Kongresse und Tagungen (dabei Großkundgebung mit Ley und Schirach 1939, „Tag der Freiheit“, 2 Bde, 1942-1944, Landeskulturtage), Einladung von Ausländern.

- Organisation und Geschäftsverteilung (104 Bde, 1939-1945), u. a. der Dienststrafkammer (1942-1943), der Regierung Litzmannstadt (2 Bde, 1941), der Landratsämter und Stadtverwaltungen (18 Bde, 1941-1943), Verwaltungsvereinfachung, Behandlung von Geheimsachen, Schriftgutverwaltung (mit Aktenplänen und -verzeichnissen), Freisetzung von Kräften für die Kriegswirtschaft (1944); Haushalt (7 Bde, 1940-1944), dabei Deutsch-italienische Vereinbarung für die Umsiedler aus Südtirol (1940-1943).

- Personalangelegenheiten (20 Bde, 1940-1944), u. a. Uk-Stellung, Kameradschaftsdienst, Abordnung zur Polizeireserve, Einsatz bei Schanzarbeiten, Hilfsdienst bei der Gendarmerie.

- Haus- und Gebäudeverwaltung (11 Bde, 1940-1945), u. a. Wohnungen deutscher Angestellter und Beamter, Verdrängung von Polen (8 Bde, 1940-1944).

- Haushalts-, Kassen- und Rechnungswesen (145 Bde, 1939-1944) mit Haushaltsplänen und Jahresabschlüssen, u. a. Bereitstellung und Verwendung von Mitteln für Aufbaudarlehen, OT-Oberbauleitung Posen, Befestigungsarbeiten, Schloßverwaltung, Landeskulturverwaltung, einzelne Betriebe (u. a. Vorkriegsschulden Hermannsbad, 5 Bde, 1940-1943), einzelne Kreise, Stadt Posen und Reichsuniversität Posen. Der Teilbestand der GKW (18 Bde. 1939-1940) betrifft u. a. die Beschlagnahme von jüdischem und polnischem Eigentum (1939-1940) und enthält Aufstellungen von Gütern und Grundeigentum von Besitzern verschiedener Nationalitäten (1942).

- Raumordnung und Landesplanung (20 Bde, 1939-1944), dabei Aufzeichnungen des Generalreferenten W. Richert, „Posener Briefe“ von Ltn. Dörr, Unterlagen über Planungen für Sachsen, Österreich und die Neugestaltung von Prag.

- Rechtspflege und Bücherei (99 Bde, 1940-1944), u. a. Rechtsangleichung, Gemeindeordnungen, Berichte des Gaupresseamtes, auch Reste von Schriftverkehr des Chefs der Zivilverwaltung in Posen (1939-1940), „Gausonderdienst innere Front“.

- Preisbildung und -überwachung (66 Bde, 1939-1944) mit Mitteilungsblättern, Preisfestsetzung in Handel und Gewerbe, für Edelmetalle, im Verkehrs- und Versicherungswesen.

- Wohnraumbewirtschaftung (25 Bde, 1940-1944), u. a. Verbot der Zweckentfremdung, Listen zugewiesener Grundstücke und Wohnungen von Polen.

- Statistik (154 Bde, 1940-1944) mit allgemeinen Bestimmungen (10 Bde), Bevölkerungs- (62 Bde), Finanz- (5 Bde), Gewerbe- (4 Bde), Landwirtschafts- (42 Bde), Sozial(6 Bde), Binnenschiffahrtsstatistik (3 Bde), dabei auch zur Bevölkerungsentwicklung Lettlands (2 Bde, 1941-1943). 
- Verfassung: Reichsgebiet (5 Bde, 1939-1941), u. a. Berichtigung der Gau- und Kreisgrenzen, Vertretung der eingegliederten Ostgebiete im Reichstag. - Hoheitssachen (40 Bde, 1940-1945), u. a. nationale Symbole, Verkehr zwischen Polen und Deutschen, Aktenkassationen in Archiven (1939-1944), Verleihung von Auszeichnungen, Feiertagsrecht, Einbürgerungsanträge, Eheschließung zwischen Deutschen und Polen (13 Bde, 1940-1944, dabei auch 2 US-Staatsangehörige, 1942-1944), Namensänderungen, Personenstandsveränderungen, Beurkundungen, Kreissippenämter (1942-1943). - Rechtsangleichung (44 Bde, 1940-1944), u. a. Einführung der 13. Verordnung zum Reichsbürgergesetz, Ausländerpolizeiverordnung.

- Verwaltungsaufbau (79 Bde, 1939-1944) mit Anschriften der Behörden (3 Bde, o. D.), Tätigkeits- und Lageberichten von Landräten (7 Bde, 1939-1943), Vereinfachung der Verwaltung, Aufbau des Gauarbeitsamtes (1940-1942), der Wasserstraßen-, Bau-, Justiz- und Finanzverwaltung, Organisation der NSDAP-Gauleitung und der HJ, ausländische Konsulate (1939-1941), auch Verordnung über staatenlose Kinder polnischen Volkstums, Pflege der deutschen Sprache.

- Volkstum, politische und kirchliche Angelegenheiten (111 Bde, 1940-1944) mit allgemeinen gesetzlichen Bestimmungen (4 Bde) und Akten betr. deutsches (4 Bde) und fremdes Volkstum (27 Bde). Von größerer Bedeutung ist ein Warschauer Teilbestand mit Unterlagen zu Nationalitäten-, Rassen- und Volkstumsfragen (22 Bde, 1940-1943), Umsiedlung der Balten- und Wolhyniendeutschen (11 Bde, 1939-1944), Behandlung von Fremdarbeitern (12 Bde, 1940-1944), Umsiedlung der Polen (33 Bde, 1940-1944), Beschlagnahme von polnischem, jüdischem und schwedischem Besitz, Widerstandsbewegung (23 Bde, 1941-1944, u. a. Armija krajowa und „Schwert und Pflug“). Die Warschauer Akten über Kirchenfragen (101 Bde, 1940-1944) dokumentieren die Beschlagnahme von Kircheneigentum, Gebäuden, Klöstern und Ländereien, Kultgegenständen, die Überführung von Kirchenbeamten und Geistlichen in andere Berufe, die Einziehung von Kirchenbüchern, Feiertagsrecht, Wehrmachtsgottesdienste in polnischen Kirchen (1941-1944).

- Reichsverteidigung (16 Bde, 1940-1944).

- Polizei und Verkehrswesen (44 Bde, 1940-1944).

- Kommunalaufsicht (604 Bde, 1940-1944), u. a. Ortsnamenänderungen (123 Bde), Bürgermeister und Beamte (273 Bde), Gemeindefinanzen (26 Bde) und -sparkassen (24 Bde).

Aus der Zuständigkeit der Abteilung I enthält der Warschauer Teilbestand weitere Akten über Rassen- und Volkstumsfragen (10 Bde, 1941-1944), die Ansiedlung von Deutschen (9 Bde, 1940-1941) und die Aussiedlung von Polen und Juden (1939-1941), die Erfassung von Kunst- und Wertgegenständen aus Schlössern und Gütern (1940), Beschlagnahme von polnischem und jüdischem Eigentum (2 Bde, 1940-1941), Kirchenangelegenheiten (12 Bde, 1940-1944). Vorhanden sind ferner Listen zwischen Oktober 1939 und Februar 1940 festgenommener Polen und von Polen, Juden und Russen, die vom 23. 11. 39 bis 10. 1. 45 durch Polizei und Gestapo erschossen wurden, sowie von Häftlingen des Arbeitslagers Wasow (1942) und von polnischen Kindern in Waisenhäusern (1942-1944).

- Hauptpersonalamt (184 Bde, 1939-1944): u. a. Stellenpläne, Beamtenrecht, Überprüfung und Erfassung Angestellter einzelner Ämter (dabei Reichsarchiv, 5 Bde, 19391944), Überprüfung der konfessionell gebundenen Gefolgschaftsmitglieder, Verleihung des Kriegsverdienstkreuzes und anderer Auszeichnungen (47 Bde, 1942-1944), Bewerbungen und Einstellungen (33 Bde, 1940-1944, dabei Verwendung von Admiral Hans 
Bachmann, 1943), Dienststrafverfahren gegen Angestellte (1941-1944), Tarifrecht, Wohnungsfürsorge, Urlaub (10 Bde, 1941-1944), Personalakten, Ernennungen und Abordnung (28 Bde, 1940-1944), Wehrdienst der Landräte von Posen und Litzmannstadt (2 Bde, 1941-1943), Übersichten über den Personalbestand (35 Bde, 1940-1944), Trennungsentschädigungen (25 Bde, 1940-1944).

Abteilung II, Gesundheitswesen und Volkspflege (454 Bde, 1940-1944): Organisation und Geschäftsführung (65 Bde), Medizinalverwaltung (170 Bde), Angelegenheiten der Ärzte und Heilhilfsberufe (117 Bde), Erb- und Rassenpflege (17 Bde), öffentliche Fürsorge (65 Bde), Jugendwohlfahrt (28 Bde), Veterinärwesen (52 Bde).

Abteilung III, Erziehung, Unterricht, Kultur und Gemeinschaftspflege (341 Bde, 1940-1944): Organisation und Geschäftsführung (53 Bde), Wissenschaft (3 Bde), Volksund Mittelschulen (229 Bde), Kultur (14 Bde betr. Bibliotheken und Museen), Landjahrlager (42 Bde).

Abteilung IV, Landwirtschaft, Siedlung, Umlegung und Wasserwirtschaft (16 Bde, 1940-1944), u. a. Pläne zur äußeren Gestaltung der deutschen Dörfer.

Abteilung V, Wirtschaft und Arbeit (145 Bde, 1940-1944): Wirtschaft (87 Bde), Geld und Finanzen (38 Bde), insbesondere Gewährung von Krediten, Arbeit (2 Bde), Versicherungen (6 Bde), Aktion „Warschau“ (10 Bde betr. Enteignungen in Verbindung mit dem Warschauer Aufstand), Zeitungsausschnitte (1 Bd).

Abteilung VI, Forstwirtschaft (6 Bde, 1940-1942).

Abteilung VII, Bauwesen (361 Bde, 1940-1944, davon 326 betr. Hochbau): u. a. Pläne zum Ausbau der Städte, der Residenz Greisers in Ludwikow, Umbau des Schlosses in Posen, Bau von Polizeikasernen und -posten, von Gefängnissen und Einrichtung eines Lagers in Starolec (Stadtteil von Posen) nach Abgabe des Forts VII für militärische Zwecke.

Abteilung VIII, Wasserstraßendirektion (187 Bde, 1940-1944, dabei Schiffsverkehr in Landsberg/Warthe).

Gauwohnungskommissar, Wohnungs- und Siedlungsamt (160 Bde): u. a. Planung von Wohnungen für Umquartierte aus Luftkriegsgebieten.

Aus der Gauselbstverwaltung sind folgende Akten in Posen überliefert (358 Bde, 1939-1945, Best. 301):

- Abteilung I, Finanz- und Wirtschaftsangelegenheiten: Hochbauverwaltung (119 Bde, 1939-45). - Organisation der Gauselbstverwaltung, Besoldung (28 Bde, 1940-1944, mit Stellenplan). - Presseangelegenheiten (3 Bde, 1939-1940). - Haushalt (29 Bde, 19411944). - Verwaltungsberichte (18 Bde, 1941-1944). - Bausachen (19 Bde, 1942-1945). - Bilanzen verschiedener Betriebe (17 Bde, 1939-1944). - Wohnungsfürsorge (13 Bde, 1940-1944). - Aufsicht über Versicherungen (2 Bde, 1940-1944). - Forderungen und Rückgabe von Betrieben und anderem Eigentum (10 Bde, 1940-1944). - Strafsachen (7 Bde, 1940-1944). - Rechtsfragen im Siedlungswesen (2 Bde, 1941-1944) und der Haupttreuhandstelle Ost. - Jugendrecht. - Kriegsschäden (2 Bde, 1941-1945). - Rechtsverordnungen (19 Bde, 1939-1944). - Altschuldenregelung (5 Bde, 1941-1944).

- Abteilung II, Landesjugendamt, öffentliche Fürsorge, Jugendwohlfahrt und Jugendhilfe (98 Bde, 1939-1945): Rundschreiben, Organisation (12 Bde, 1941-1944). - Volkspflege, Fürsorge und Beihilfen (6 Bde, 1940-1944). - Fürsorgeerziehung (18 Bde, 1940 1945), Ausbildung von Fürsorgezöglingen (30 Bde, 1940-1944), Gauerziehungsheime (20 Bde, 1940-1944), kirchliche Erziehungseinrichtungen (12 Bde, 1939-1944). 
- Abteilung III, Allgemeine und kulturelle Verwaltungsangelegenheiten: Beschlagnahme und Verwaltung von Kirchenbesitz (551 Bde, 1940-1944) mit Vorschriften und Verordnungen (2 Bde, 1940-1944), Einzelnachweise über Pfarrhäuser, Schwesternhäuser, Grundstücke, Kapellen, Kirchen, Krankenhäuser, Güter, Priesterseminare (549 Bde, 1940-1944). - Tuberkulosefürsorge (13 Bde, 1940-1944, dabei Unterbringung von Lungenkranken aus Straflagern, 1942). - Kulturelle Angelegenheiten (3 Bde, 1939-1942, dabei Leihvertrag über Gemäldegalerie Raczynski, 1941-1942).

Unverzeichnet ist ein nicht archivwürdiger Teilbestand (1937 Bde).

Auf Mikrofilm (37 Rollen von 243 Bden, Best. PL-089 und -019) sind im BA P vorhanden die Rundschreiben und Runderlasse, Niederschriften über Abteilungsleiterbesprechungen, Geschäftsverteilungs- und Aktenpläne, Akten in Presseangelegenheiten, über Grenzberichtigungen, Neugestaltung deutscher Städte und Dörfer, Festigung des deutschen Volkstums (insbesondere 4 Bde Sitzungsprotokolle der Zentralstelle der deutschen Volksliste), Unterbringung von Juden in Ghettos, Organisation der NSDAP und der HJ, Landjahrlager, Verleihung von Auszeichnungen, Einsatz der Schutzpolizei und Gendarmerie, Jugendverwahrlager, Aktion „Warschau“ (Verzeichnis des Beutegutes und dessen Verwertung), Einsatz polnischer Ordensgeistlicher in der Gauanstalt Schmückert. Aus einem Teilbestand im IZP stammen Kopien von Korrespondenz der Abteilung für Kirchenfragen (1941-1943) über Benennung und Bestätigung der Vertreter religiöser Gemeinschaften im Warthegau, Zulassung von Pfarrern, Beschlagnahme und Freigabe kirchlichen Vermögens. Weitere Kopien und einzelne Unterlagen über den Verwaltungsaufbau (1940, die Räumung 1945) und den Haushalt der Gauselbstverwaltung (7 Bde, 1940-1943, dabei Bericht der Abteilung Kulturpflege für 1939/40, u. a. über das Gausippenamt) befinden sich im BA KO (Best. R 138 II), in dem außerdem 122 Berichte von „Angehörigen der politischen Führungsschicht“, darunter der Adjutant Greisers, der Leiter der Abteilung I und der Generallandschaftsdirektor (Best. Ost-Dok. 8), und weitere Berichte über die Verwaltung (dabei Rechenschaftsberichte Greisers 1941 und 1943) vorliegen (Best. Ost-Dok. 13).

Lit:: Z. JANOWICZ: Ustroj administracyjny ziem polskich wcielonych do Rzeszy Niemieckiej 1939-1945. Tzw. Okregi Kraju Warty i Gdanska-Prus Zachodnych. 1951. - K. M. POSPIESZALSKI: Niemiecka Lista Narodowa w „Kraju Warty“. 1949. - GRUNDRISS zur deutschen Verwaltungsgeschichte 1815-1945. Reihe A, 2: Posen/Provinz Grenzmark Posen-Westpreußen. 1975.

\subsection{Staatskanzleien und Gesamtstaatsministerien der Länder}

\subsubsection{Sächsische Staatskanzlei}

DD

Nur ein kleiner Teil der Akten blieb nach den Luftangriffen auf Dresden erhalten; überwiegend stammt er aus der Amtszeit des Ministerpräsidenten Manfred v. Killinger (1933-1935), weniger aus der Zeit der Vereinigung der Ämter von Reichsstatthalter und Ministerpräsident in der Person des Gauleiters Martin Mutschmann. Sie betreffen u. a.: Neubildung des Landtages (2 Bde, 1933), Kreisstände und Stände der Oberlausitz (1933-1940), Berufung von Vertretern zum Landkreistag (1939-1940), Bestellung Killingers als Reichskommissar (1933-1934), deutsche und tschechoslowakische Kommunisten (3 Bde, 1934-1935), „Sächsische Staatszeitung“ (1903-1934), Dienststrafverfahren (1932-1935), Staatshaushalt (1944-1945), Umschulung von Kriegsbeschädigten durch 
die Hauptfürsorgestelle (Einzelfälle, 22 Bde, 1942-1945), Auslagerung von Kunst- und anderen Sammlungen (56 Bde, 1939-1946), Einladungen (4 Bde, 1933-1934), Sächsisches Verwaltungsblatt (5 Bde, 1933-1935). Vorhanden sind ferner Registraturhilfsmittel (70 Bde, 1933-1942), Urschriften von Gesetzen (1935-1942) und Haushaltstitelbücher der Landesplanungsgemeinschaft Sachsen (8 Bde, 1938-1940).

Von der Presse- bzw. Nachrichtenstelle der Staatskanzlei stammt eine Zeitungsausschnittsammlung (2265 Bde, 1918-1942) mit Berichten überregionaler und sächsischer Zeitungen in folgender Gliederung:

- Reichsverfassung und -organe; Verfassung, Landtag und Regierung Sachsens; ehemalige Herrscherhäuser; Innenpolitik; Justiz; Finanzen; Wirtschaft; Verkehr; Arbeit; Sozialfürsorge, Wohnungs- und Siedlungswesen; Gesundheitswesen, Versicherungen, Sport; Kultur; Militärangelegenheiten, Versorgung der Kriegsteilnehmer; andere deutsche Länder; Versailler Vertrag; Außenpolitik.

Aus der Wehrwirtschaftlichen Abteilung sind Akten über einzelne Betriebs- und Personalüberprüfungen zur Abwehr von Spionage und Sabotage durch die Gestapo (1935-1945) überliefert (BA DH).

Eine bedeutende Ergänzung für die ersten Jahre nach 1933 bieten mit der Überlieferung des Ministeriums der auswärtigen Angelegenheiten vereinigte Akten. Sie betreffen u. a. Reichspräsidenten (1919-1934) und Reichsrat (1922-1934), politische Verhältnisse in Sachsen (2 Bde, 1902-1934), in den thüringischen Staaten (1907-1934) und Schaumburg-Lippe (1926-1934), Fremdenlegion (1929-1935), Flüchtlingsfürsorge (1923-1934), Deutschtum in Polen (1928-1935), Beschäftigung ausländischer Arbeitskräfte (4 Bde, 1925-1934), Reparationen (1930-1934), Internationale Elbekommission (13 Bde, 1920-1935, darin: 6 Bde Tagungsprotokolle 1933-1935), Schwerkriegsbeschädigte (1919-1934), Volkszählungen (1902-1935), Militäranwärter (1931-1935), Kriegsgräber und -denkmäler (1872-1935), Rüstungsexport (1914-1934), Bekämpfung politischer Ausschreitungen (1931-1934), kommunistische Bewegung (4 Bde, 19311935), Reichstagsbrandverordnung (3 Bde, 1933-1935), Beschwerden der polnischen, tschechoslowakischen und anderer Vertretungen wegen Mißhandlungen von Staatsangehörigen (15 Bde, 1933/34), Nachprüfung von Schutzhaftfällen (3 Bde, 1934/35), Parteigerichte der NSDAP (1934), Reichs- (9 Bde, 1922-1935) und Landesbeamte, -angestellte und -arbeiter (ca. 17 Bde, 1902-1935, überwiegend Einzelfälle), Reichs- (ca. 15 Bde, 1901-1935) und Landesfinanzen (ca. 10 Bde, 1870-1935), Steuern und Zölle (ca. 60 Bde, 1875-1935), Banken und Sparkassen (ca. 20 Bde, 1896-1935), Sozialpolitik (ca. 90 Bde, 1886-1935), Wirtschaft und Verkehr (ca. 50 Bde, 1901-1935), Gewerbe und Industrie (ca. 95 Bde, 1899-1935), Groß- und insbesondere Außenhandel (53 Bde, 1855-1935); Vereinigungen, Genossenschaften, Gesellschaften (10 Bde, 19041935); Land-, Forst-, Wasserwirtschaft (ca. 75 Bde, 1884-1935); Post, Telegraf, Funk (14 Bde, 1904-1935), Eisenbahnwesen (27 Bde, 1880-1935), Schiffahrt (17 Bde, 18981935); Luftfahrt, Straßenverkehr und -bau (ca. 35 Bde, 1898-1935); Ausstellungen (8 Bde, 1900-1936); Justiz (26 Bde, 1858-1935); Polizei (20 Bde, 1905-1935), Paßwesen (2 Bde, 1931-1935), Ausweisungen, Auslieferungen (2 Bde, 1922-1934); Medizinal- und Veterinärwesen (ca. 75 Bde, 1880-1935); Kultur, Kunst und Wissenschaft (ca. 40 Bde, 1875-1935); Ausstellungen, Kongresse, Museen (4 Bde, 1904-1935), Bildungswesen (ca. 45 Bde, 1898-1935), Kirchenangelegenheiten (8 Bde, 1886-1935).

Lit.: GRUNDRISS zur deutschen Verwaltungsgeschichte 1815-1945. Reihe B, Bd 14: Sachsen. - W. BRAMKE: Vom Freistaat zum Gau. 1983. 
1.2.2 Thüringisches Staatsministerium - Präsidialabteilung WE Am Gesamtbestand (7 lfm, 1920-1945) haben die Akten aus der Amtszeit des Ministerpräsidenten (ab Mai 1933) Willy Marschler einen von Jahr zu Jahr geringeren Anteil. Vorhanden sind u. a. Niederschriften über Sitzungen und Protokolle des Staatsministeriums (3 Bde, 1927-1935) mit Beiakten (2 Bde, 1932-1937), Inhaltsverzeichnissen und Sachregister (6 Bde, 1933-1937), Akten über Entlassung des Kultusministers Fritz Wächtler (1936), Vertretung des Landes in Berlin u. a. durch Gauwirtschaftsberater Dr. Walter Schieber (1939-1944), Vereidigung der Beamten (1919-1942), Auszeichnung von Beamten im allgemeinen (1926-1945) und mit Treuedienst-Ehrenzeichen und Ehrenkreuz für Frontkämpfer (6 Bde, 1934-1943), Auszeichnungen für Lebensretter (3 Bde, 1934-1937), Patenschaften für Kinderreiche (2 Bde, 1933-1944), Dienststrafverfahren (3 Bde, 1932-1937), Einzelpersonalakten (58 Bde, 1882-1945). Die Akten des Landtags reichen zum Teil bis 1934 und dokumentieren die vier letzten Sitzungen des Jahres 1933 mit Anträgen und Petitionen, die Auflösung der Fraktionen von SPD und KPD und Personalangelegenheiten des NSDAP-Abgeordneten Paul Hennicke.

Lit.: GRUNDRISS zur deutschen Verwaltungsgeschichte 1815-1945. Reihe B, Bd 15: Thüringen.

\subsubsection{Mecklenburgisches Staatsministerium SN, Best. 2110}

Aus dem nur bis 1934 von den Ministerpräsidenten Walter Granzow (1933) und Hans Egon Engell, seitdem von dem einzigen Staatsminister Friedrich Scharf geleiteten Amt sind relativ wenig Akten aus der NS-Zeit überliefert. Sie enthalten Gesetze und Rundschreiben des Staatsministeriums (9 Bde, 1937-1944), Gesuche an verschiedene Ministerien (3 Bde, 1929-1945) und betreffen u. a.:

Wappen, Landesfarben und Dienstsiegel (1921-1945), Organisation der Ministerien (1900-1945), Geschäfts- und Dienstbetrieb (2 Bde, 1925-1947), Staatsgerichtshof (19251935), Errichtung einer Staatsbank (1938-1940), Personalsachen (11 Bde, 1850-1943), Dienststellenverwaltung (3 Bde, 1920-1945), Rechte an den drei Landesklöstern (19101939), Landtag (2 Bde, 1921-1935), Verhältnis zur NSDAP (1937-1938), Ariernachweis für Beamte (1934-1944), Bevölkerungs- und Rassenpolitik (1934-1940), Verleihung der Lebensrettungsmedaille (1922-1943).

Lit.: GRUNDRISS zur deutschen Verwaltungsgeschichte 1815-1945. Reihe B, Bd 13: Mecklemburg.

\subsubsection{Anhaltisches Staatsministerium}

OBA

Nur ein kleiner Teil des Gesamtbestandes (ca. 100 lfm, 1862-1940) enthält Schriftgut aus der Amtszeit des einzigen Staatsministers Alfred Freyberg (1932-1945). Dazu gehören Akten über Justiz und Justizverwaltung (38 Bde, 1868-1935), darunter Zivilrecht (17 Bde, 1868-1935), Strafrecht und Strafvollzug (9 Bde, 1920-1935, darin: Ermittlungen gegen Prof. Hugo Junkers 1933-1934, Jahresbericht der Kriminalbiologischen Sammelstelle, Eingaben und Beschwerden von jüdischen und anderen Gefangenen 1932-1935), Finanzverwaltung (3 Bde, 1899-1939), Wirtschafts-, Landwirtschafts- und Lehenssachen (3 Bde, 1829-1935), Militär- und auswärtige Angelegenheiten (3 Bde, 1920-1935), Polizei (4 Bde, 1934-1937), Gesundheitswesen und Soziales (1923-1934).

Lit.: GRUNDRISS zur deutschen Verwaltungsgeschichte 1815-1945. Reihe B, Bd 16, Teil 2: Anhalt. 


\subsection{Preußische Oberpräsidien und Provinzialverwaltungen}

\subsubsection{Oberpräsidium der Provinz Mark Brandenburg, Berlin}

P, Pr. Br. Rep. 1

Da der Dienstsitz des Oberpräsidenten, der Gauleiter Wilhelm Kube (1933-1936) und Emil Stürtz (1937-1945), in Berlin-Charlottenburg zerstört wurde, sind im Gesamtbestand (92,5 lfm, 1773-1949) nur wenige Akten nach 1934 überliefert. Sie stammen meist aus Abteilung I, u. a. Runderlasse an die Beamten, Angestellten und Arbeiter des Oberpräsidiums (1934-1940), Berichte über die politische Lage (4 Bde, Juni 1935-Januar 1936) und betreffen ferner Notdienstverpflichtungen von Krankenhausärzten (1942-1945), Gesuche auf Ein- und Wiedereinstellung in die Stadtverwaltung Berlins (2 Bde, 1930-1936), Eingaben und Beschwerden über den Provinzialverband (19301934) und Zusammenarbeit von NSV und Behörden (1935-1936). Ein Teilbestand im GStA (Brandenburg. Rep. 1) enthält Akten über die Verwaltung von Berlin (16 Bde, 1933-1934) und Wirtschaftslageberichte (1942-1945).

\subsubsection{Provinzialverwaltung Brandenburg, Potsdam P, Pr. Br. Rep. 55}

Der Bestand, dessen älteste Akten 1772 einsetzen und der bis 1949 Zuwachs erhielt, enthält aus der Zeit von 1933 bis 1945 Schriftgut folgender Teilprovenienzen:

- Landesdirektor bzw. Landeshauptmann (zuletzt v. Arnim-Rittgarten) und andere leitende Beamte (insgesamt 544 Bde, 1914-1945), darin: Allgemeines (17 Bde, 1931-1944), Fachabteilungen der Hauptverwaltung (25 Bde, 1936-1940), nachgeordnete Anstalten und Einrichtungen (2 Bde, 1936-1939), Verkehrswesen (15 Bde, 1930-1944), Sparkassen und Versicherungen (13 Bde, 1933-1944), Stadtschaft (4 Bde, 1924-1942), Landgesellschaft „Eigene Scholle“ (6 Bde, 1931-1943), Märkisches Elektrizitätswerk (20 Bde, 1916-1944), Brandenburgische Heimstätte (6 Bde, 1935-1944), Kurmärkische Kleinsiedlung (6 Bde, 1934-1944), Deutscher Gemeindetag (5 Bde, 1933-1939), Wirtschaftsund Prüfungsverbände (4 Bde, 1933-1938), Reichsverkehrsgruppe Schienenbahnen (5 Bde, 1934-1941), Landesplanung (13 Bde, 1920-1941), Arbeitsgemeinschaft der Landeshauptleute (1933-1944), Angelegenheiten der Provinz Grenzmark Posen-Westpreußen (9 Bde, 1929-1942), Provinzialrat (3 Bde, 1940-1944), Aufsichtsratstätigkeit (9 Bde, 19341938), Gauheimstättenbund (7 Bde, 1934-1940), Zusammenarbeit mit der NSDAP und ihren Gliederungen (31 Bde, 1934-1939); Aufgaben des Ersten Landesrates, Landesplanung, Siedlungs- und Wohnungswesen (45 Bde, 1930-1944), Beamtenangelegenheiten (7 Bde, 1933-1942), Landeskultur- und Wasserwirtschaft (11 Bde, 1930-1943), Verkehr (17 Bde, 1933-1944); Angelegenheiten der Abteilungen I (37 Bde, 1933-1943), II (24 Bde, 1933-1940), III (6 Bde, 1933-1939), IV (3 Bde, 1933-1944), V (1930-1938), VI (5 Bde, 1930-1938), VII (3 Bde, 1927-1942), VIII (1935-1936), IX (8 Bde, 1932-1942), X (3 Bde, 1932-1943), XI (4 Bde, 1935-1942) und XII (3 Bde, 1936-1942); Handakten der Medizinalräte (22 Bde, 1918-1939).

- I Zentralabteilung (insgesamt 3112 Bde, 1861-1943):

- - Alte Registratur: u. a. Provinzialrat (6 Bde, 1933-1936), Wahlen zu Behörden und Kommissionen (4 Bde, 1903-1938), Organisation der Provinzial- und der -finanzverwaltung (37 Bde, 1900-1938), Konferenzen, Revisionen und Besichtigungen (13 Bde, 1913-1937), Dienstbetrieb (92 Bde, 1877-1943), Beamtenangelegenheiten (253 
Bde, 1895-1943), Stellenakten (53 Bde, 1906-1943), Prozeß-Sachen (7 Bde, 1931-1939), Beschwerden gegen Verwaltungsangehörige und Anstalten (23 Bde, 1918-1937).

- - Neue Registratur: Provinzialgebiet und -organe (16 Bde, 1936-1944), Verwaltung und Geschäftsführung (289 Bde, 1920-1944), Organisation, Organe und Satzungen von Provinzialinstituten, Sonderverwaltungen und Unternehmungen (40 Bde, 1928-1945), Personalangelegenheiten (433 Bde, 1903-1945) mit Gehaltsblättern (71 Bde, 19011945), Haushaltspläne, Geschäftsberichte, Statistik, Presse (94 Bde, 1928-1945), Versicherungseinrichtungen, Brandenburgische Witwen- und Waisenversorgungsanstalt (345 Bde, 1885-1945) und Ruhegehaltskasse (163 Bde, 1926-1945) mit Personalbögen (74 Bde), Unfallfürsorgekasse für Kommunalbeamte (62 Bde, 1937-1945), Zusatzversorgungsanstalt des Reiches und der Länder (1938/39), Statistik im allgemeinen (67 Bde, 1927-1945), Bevölkerungs- (19 Bde, 1936-1942), Preis- und Versorgungs- (88 Bde, 1937-1945), Verbraucher- (9 Bde, 1943-1945), Finanz- (47 Bde, 1923-1945), Krankenund Fürsorgestatistik (30 Bde, 1926-1945), Arbeitskräftebilanz (124 Bde, 1941-1945), Urkundsbeamte (90 Bde, 1879-1943).

- II Finanzabteilung (insgesamt 1134 Bde, 1876-1945), darin:

Allgemeines und Hauptetat (53 Bde, 1876-1944), Provinzialsteuern (56 Bde, 18761945), Schuldbuch (8 Bde, 1878-1939), Innerer Dienst (19 Bde, 1905-1944), Abteilungen und Sonderverwaltungen des Provinzialverbandes (20 Bde, 1897-1940), Auseinandersetzungen mit Groß-Berlin (52 Bde, 1908-1943), Brandenburgische Landeshauptkasse (15 Bde, 1912-1941); Anleihen für Provinzial- und Privatunternehmen im allgemeinen (36 Bde, 1877-1943) und Einzelfälle (87 Bde, 1912-1945), Meliorationsvorhaben (25 Bde, 1904-1944), Beseitigung von Hochwasserschäden (4 Bde, 19211938), Straßenbau (27 Bde, 1908-1944), Eisenbahnbau (9 Bde, 1892-1945), Wohnungsbau (12 Bde, 1922-1945), Bau von Provinzialanstalten und Veräußerung von Provinzialgrundstücken (16 Bde, 1905-1945), Notstandsarbeiten und Arbeitsbeschaffungsprogramm (10 Bde, 1915-1945), Unterstützungsfonds und Hilfskassen (4 Bde, 1880-1940); Brandenburgische Provinzialbank (59 Bde, 1878-1943), Märkisches Elektrizitätswerk (132 Bde, 1915-1944); Brandenburgischer Sparkassen- und Giroverband (4 Bde, 1921-1942), Provinziallebensversicherungsanstalt und Landesversicherungsanstalt (32 Bde, 1903-1943), Stadtschaft (20 Bde, 1911-1942), Feuersozietät (6 Bde, 19241936); Landesplanung im allgemeinen (63 Bde, 1899-1945), Landesplanungsverband Brandenburg-Mitte (12 Bde, 1928-1943), Landesplanungsgemeinschaft Niederlausitz (15 Bde, 1928-1939), Siedlungs- und Wohnungswesen im allgemeinen (36 Bde, 19081939), Kreissiedlungsgesellschaften (29 Bde, 1919-1943), Landgesellschaft „Eigene Scholle“ (13 Bde, 1911-1944), Siedlungsgesellschaft „Brandenburgische Heimstätte“ (39 Bde, 1923-1945); Landarbeiterwohnungsbau: Allgemeines (148 Bde, 1921-1945); Landeshauptkasse (25 Bde, 1919-1945).

- III Straßenbauabteilung (insgesamt 2949 Bde, 1827-1946): u. a. Übernahme, Bau, Unterhaltung und Abgabe von Chausseen und Brücken (42 Bde, 1929-1940), Prozesse (1928-1935); Grundeigentumsverhältnisse (11 Bde, 1931-1935), Provinzialstraßen in unmittelbarer Unterhaltung der Provinz (38 Bde, 1930-1935) und der Kreise (43 Bde, 1930-1941), Renten- und binnenstädtische Zuschüsse (43 Bde, 1932-1942), Bauprämien, Wegebauhilfe, Wegeverzeichnisse (11 Bde, 1903-1944), Arbeitsbeschaffungsprogramm (53 Bde, 1932-1940); Landstraßenverwaltung (541 Bde, 1930-1946), einzelne Straßenbauämter; Verwaltung von Reichsstraßen (246 Bde, 1926-1945); Handakten des Landesbaurates Kluge (16 Bde, 1914-1942); Bestandsbücher, Inventare, 
Feldbücher, Grenz-, Vermessungs- und Katasterunterlagen für Reichs- (581 Bde, $1827-$ 1945) und Landstraßen (299 Bde, 1877-1946).

- IV Eisenbahnabteilung (insgesamt 290 Bde, 1905-1947): Allgemeines (50 Bde, 1931-1945) und Spezialakten über einzelne Strecken.

- V Hochbauabteilung: Maschinentechnik (19 Bde, 1938-1945), Bautechnik (43 Bde, 1907-1945).

- VI Wasserwirtschaft und Landeskultur (insgesamt 911 Bde, 1836-1946), u. a. Verwaltungs-, Personal-, Tarifangelegenheiten (31 Bde, 1911-1945), Meliorationsförderung und Ödlandkultivierung (272 Bde, 1894-1945), Hochwasser- und Notstandsaktionen (42 Bde, 1924-1945), Hochwassermeldungen (18 Bde, 1913-1945), Wettermeldungen (5 Bde, 1935-1945), Unterhaltung einzelner Flußläufe; Unterhaltung von Stauwehren (61 Bde, 1913-1945) und Brücken (17 Bde, 1920-1946), Pegel-Sachen (13 Bde, 1911-1944) und Pegelstammbücher, Wasserstandslisten und Wasserstandsbeobachtungen; Karten, Pläne, Katasterunterlagen (1942-1943).

- VII a Landeswohlfahrts- und Landesjugendamt (insgesamt 280 Bde, 18801945), u. a. Allgemeine Wohlfahrtspflege (27 Bde, 1922-1945), Fürsorge für Umsiedler und Ausländer (15 Bde, 1889-1945), Wanderer (22 Bde, 1921-1945), Taubstumme (31 Bde, 1912-1953), Bekämpfung von Augenkrankheiten (2 Bde, 1935-1939), Blindenfürsorge (15 Bde, 1886-1947), Jugendpflege (31 Bde, 1913-1943), Kleinkinder- und Mütterfürsorge (15 Bde, 1917-1943), Fürsorgeerziehung (41 Bde, 1904-1945), Adoptionsvermittlung (18 Bde, 1918-1945), Volkspflegeschulen (4 Bde, 1918-1945).

- VII b Gesundheitsverwaltung (insgesamt 363 Bde, 1879-1946), u. a. Allgemeines (8 Bde, 1934-1944), Heil- und Pflegeanstalten und Krankenhäuser (8 Bde, 1879-1945), Hebammen- und Säuglingsschwesternausbildung (22 Bde, 1907-1943), Kinderspeisungen (50 Bde, 1926-1938), -erholung und -verschickung (33 Bde, 1925-1943), Suchtbekämpfung (4 Bde, 1883-1942), Tuberkulosefürsorge (224 Bde, 1904-1945).

- VIII Hauptfürsorgestelle für Kriegsbeschädigte und Kriegshinterbliebene (22 Bde, 1926-1945).

- IX Wirtschaftsabteilung (insgesamt 2229 Bde, 1806-1945),

- - Alte Registratur: Innere Verwaltung (8 Bde, 1909-1936), Provinzialanstalten und -güter (93 Bde, 1893-1937, mit Verwaltungsberichten), Bauvorhaben für Landwirtschaftsbetriebe (19 Bde, 1919-1937), Feuerschutz und Versicherungen (34 Bde, 1885 1937), Entlohnung der Anstaltsinsassen (2 Bde, 1913-1936), Friedhofs- und Bestattungssachen (7 Bde, 1865-1936), Steuererhebungen (38 Bde, 1908-1937), Lübbener Amtsmühlen (27 Bde, 1921-1936); allgemeine Grundstücksverwaltung (5 Bde, 18931945), Viehseuchenbekämpfung und Unterstützung landwirtschaftlicher Lehranstalten (151 Bde, 1912-1945).

- - Neue Registratur: Grundstücksverwaltung (202 Bde, 1858-1945, darin 16 Bde betr. Beanspruchung von Anstalten zu militärischen Zwecken), Personalangelegenheiten (62 Bde, 1923-1945, darin 13 Bde betr. politische Betätigung der Provinzialbediensteten); Verwaltung der Provinzialanstalten und -güter, Verwaltungsaufbau und grundlegende Vorschriften (65 Bde, 1931-1948), Dienstaufsichtssachen, Besichtigungen, Beteiligungen an öffentlichen Veranstaltungen, Veröffentlichungen (56 Bde, 1934-1946), Haushaltspläne, Verwaltungsberichte und Statistik (199 Bde, 1931-1946), Büro- und Kassensachen (58 Bde, 1933-1946), Angelegenheiten der politischen Verwaltungsbezirke (3 Bde, 1936-1944), Besteuerungen (44 Bde, 1935-1946), Feuerversicherung und Feuerschutz (54 Bde, 1939-1946), Mitgliedschaft und Beteiligung an Unternehmen, 
Verbänden und Vereinen (31 Bde, 1936-1945); Betriebsführung, Lieferung und Leistungen u. a. an NSDAP (94 Bde, 1931-1945), ärztliche Fürsorge und medizinische Einrichtungen (49 Bde, 1935-1945), Betreuung der Anstaltsinsassen (37 Bde, 19351945), Land- und Forstwirtschaft (136 Bde, 1925-1945), Viehseuchenbekämpfung und -entschädigung (51 Bde, 1935-1945), Arbeitsdienst und Arbeitsbeschaffung (7 Bde, 1935-1937), Lübbener Amtsmühlen (25 Bde, 1930-1945), Auseinandersetzung mit der Stadt Berlin wegen der Anstaltsbelegung (4 Bde, 1935-1945), Luftschutz (15 Bde, 19331945), Stiftung „Haus der deutschen Frontdichter“ in Buderose (11 Bde, 1938-1945).

- XI Kulturabteilung (insgesamt 920 Bde, 1811-1945), u. a. Dienstbestimmungen (77 Bde, 1932-1945), Förderung der Wissenschaft, gemeinnützige und wissenschaftliche Vereine (42 Bde, 1892-1945), Verzeichnis der Kulturdenkmäler (79 Bde, 1932-1945), Provinzialinstitut für brandenburgische Landes- und Volkstumskunde (10 Bde, 19361945), Theater, Musik, Schriftum, Bildende Kunst, Kunstgewerbe (61 Bde, 1911-1945), Museumswesen (184 Bde, 1915-1945), Heimatkunde, Bauberatung, Volkstumsarbeit (166 Bde, 1905-1945), Bau- und Kunstdenkmalpflege, Denkmalarchiv (41 Bde, 19011945), Bodendenkmalpflege, Ur- und Frühgeschichte (73 Bde, 1910-1945), Naturdenkmalpflege und Naturschutz (15 Bde, 1933-1944), Volksbildungswesen, Ausstellungen (61 Bde, 1930-1945), Landesbücherei (44 Bde, 1933-1945), Schrifttumsarchiv (12 Bde, 1935-1944), Archivwesen (14 Bde, 1925-1945), sonstige Kulturpflege (31 Bde, 19201945, darin: 3 Bde betr. Gaupropagandaabteilung, Kulturarbeit der SA 1937 sowie 5 Bde betr. Bund Deutscher Osten).

Lit.: K. ADAMY, K. HÜBENER: Provinz Mark Brandenburg - Gau Kurmark. Eine verwaltungsgeschichtliche Skizze. 1993. S. 11-31. - GRUNDRISS zur deutschen Verwaltungsgeschichte 1815-1945. Reihe A, Bd 5: Mark Brandenburg. - G. BIRK: Spezialinventar Zwangsarbeit und Zwangsarbeiterlager in der Provinz Brandenburg. 1993, S. 449-456.

\subsubsection{Oberpräsidium der Provinz Sachsen, Magdeburg}

MD

Aus der Allgemeinen Abteilung sind aus der NS-Zeit, in der von Dezember 1933 bis Februar 1944 Curt v. Ulrich das Amt des Oberpräsidenten innehatte, u. a. Akten aus folgenden Sachgebieten vorhanden (Rep. C 20 I):

- Verfassungs- und Hoheitssachen; Reichs- und Landtagswahlen (7 Bde, 1909-1939), Betriebsrätegesetz (1934-1941), Reichsreform (5 Bde, 1919-1939), Volksabstimmung (1934-1936), Beziehungen zu deutschen und ausländischen Staaten (9 Bde, 18241944), Aus- und Einwanderung, Staatsangehörigkeit (13 Bde, 1816 1944), Vererbung von Landgütern, Familienfideikommisse (2 Bde, 1915-1939), Provinziallandtag (4 Bde, 1878-1942) und -ausschuß (7 Bde, 1874-1938), Gemeinde-, Kreis- und Provinzialsachen (12 Bde, 1870-1944), Orden und Ehrenzeichen (ca. 40 Bde, 1828-1944), Änderung von Familien- und Ortsnamen (4 Bde, 1927-1943), Begnadigungen (2 Bde, 1919-1944), Patenschaften (1817-1943).

- Geschäfts- und Ressortverhältnisse; Bezirksregierungen (ca. 80 Bde, 1817-1949, darin Berichte der Sonderbevollmächtigten und Sonderbeauftragten des Obersten SAFührers, 1932-1934, Reichspropagandastelle Magdeburg-Anhalt, 1934-1944, Ministerialerlasse, 1927-1945), Kreisbereisungen des Oberpräsidenten (20 Bde, 1933-1941, mit Berichten über die Haltung der Bevölkerung), Eingaben, Beschwerden (3 Bde, 1922-1943), Presse- und Gesetzessachen (7 Bde, 1923-1945; darin Aufgaben der Reichsschriftumskammer, Landesleitung Magdeburg-Anhalt, 1936-1941), staatseigene Gebäude und Grundstücke (6 Bde, 1931-1946), Reisen von Staatsoberhäuptern, Gedenkfeiern (8 Bde, 1902-1944, u. a. Empfang Hitlers 1938-1939), Landeskulturamt, 
Siedlungsgesellschaften (ca. 45 Bde, 1922-1946), Elbstrombauverwaltung (3 Bde, 18831944), Beamte der Regierungen Magdeburg, Merseburg und Erfurt (14 Bde, 18531945, u. a. Abstammungsnachweise), Bezirksverwaltungsgerichte (2 Bde, 1883-1941), Landratsämter (12 Bde, 1886-1944, u. a. Verfolgung eines Landrates der SPD durch die NSDAP-Kreisleitung Burg), Polizeibehörden (12 Bde, 1812-1944), Standesämter (6 Bde, 1899-1944), Landesfinanzamt (2 Bde, 1825-1945), Banken, Kreditinstitute, Sparkassen, Versicherungen (ca. 130 Bde, 1882-1946), Natur- und Denkmalpflege, Museen, Bibliotheken, Historische Kommission (18 Bde, 1906-1945), Beamtensachen (ca. 110 Bde, 1814-1946, darin: Bestimmungen zur Überprüfung der Abstammung, Unterbringung von Österreichern, Wiederherstellung des Berufsbeamtentums, Einführung des Deutschen Grußes, Blutschutzgesetz, ca. 75 Personalakten, u. a. betr. v. Ulrich).

- Finanzsachen, Haushalts-, Kassen- und Rechnungswesen (ca. 40 Bde, 1881-1944), Steuer- und Zollverwaltung (20 Bde, 1897-1944).

- Kommunalsachen, Gemeindeverfassung und -verwaltung (23 Bde, 1860-1944), Kommunalbeamte (ca. 35 Bde, 1902-1944), Gemeindefinanzen und -vermögen (53 Bde, 1870-1944), Grenzveränderungen (16 Bde, 1889-1943), Spitzenverbände (8 Bde, 19111944), Bürgerwehr und Schützengilden (3 Bde, 1839-1941).

- Kirchliche Angelegenheiten: Allgemeines, Organisation und Verwaltung (17 Bde, 1816-1944), Finanzsachen (23 Bde, 1822-1944), Ausbildung, Anstellung und persönliche Verhältnisse kirchlicher Beamter (17 Bde, 1886-1944), Patronat (2 Bde, 1845-1942), Sonn- und Feiertagsregelung (4 Bde, 1819-1942), Verwaltungs- und Kultusangelegenheiten einzelner katholischer Gemeinden, Sekten (2 Bde, 1847-1943), Judensachen und einzelne Synagogengemeinden (11 Bde, 1847-1944).

- Unterrichtsverwaltung (12 Bde, 1824-1944), Ausbildung, Anstellung und persönliche Verhältnisse der Lehrer (19 Bde, 1900-1944), Universität und Hochschulen (12 Bde, 1878-1944), höhere, Bürger-, Volks- und Landschulen (36 Bde, 1874-1944), Fach-, Berufs- und Volkshochschulen (17 Bde, 1909-1943), Blinden- und Taubstummenunterricht, Ausbildung schwachsinniger Kinder (5 Bde, 1895-1939), vermögensrechtliche Auseinandersetzung zwischen einzelnen Kirchen und Schulen (5 Bde, 1922-1941).

- Medizinalverwaltung (ca. 40 Bde, 1818-1945, darin Jahresgesundheitsberichte 19301944, Runderlasse zur Zusammenarbeit der Gesundheitsämter mit den Ämtern für Volksgesundheit der NSDAP, Durchführung der Erb- und Rassengesetze, 1926-1944), Verwendung von Arzneimitteln (2 Bde, 1931-1943), medizinisches Personal (40 Bde, 18271944), Standesvertretungen (ca. 20 Bde, 1929-1945, darin Verhandlungen des Ärztlichen Ehrengerichts), Apothekensachen (6 Bde, 1905-1944), Kranken- und Heilanstalten (7 Bde, 1915-1944), Gesundheits- und Nahrungsmittelschutz (ca. 45 Bde, 1880-1945, u. a. Viehseuchen und ansteckende Krankheiten).

- Organisation und Verwaltung der Justizbehörden (10 Bde, 1850-1944), Gesetzessammlungen, Verfahrenssachen (2 Bde, 1933-1941).

- Polizei, Allgemeines und Organisation (ca. 20 Bde, 1820-1943, darin Maßnahmen gegen Zigeuner, 1900-1939), Verordnungen (4 Bde, 1900-1943), Sicherheits- und Überwachungsangelegenheiten (1923-1940), Bau- und Bergpolizei (13 Bde, 1886-1944), Feuerpolizei (47 Bde, 1885-1945), Medizinalpolizei (7 Bde, 1891-1945), Handels- und Gewerbepolizei (6 Bde, 1913-1939), Sittenpolizei (10 Bde, 1879-1944), Verkehrspolizei (18 Bde, 1922-1943), Fremdenpolizei, Paß- und Meldewesen (12 Bde, 1822-1945, u. a. Ausweisung jüdischer Einwanderer), Kriminalpolizei, Geheime Staatspolizei (9 Bde, 1921-1944, u. a. Verfolgung von Juden nach 1933), Gendarmerie (9 Bde, 1900-1942); 
Schutzpolizei, Aufbau und Organisation und Verwaltung (ca. 40 Bde, 1920-1944), Aufgaben und Einsatz (ca. 30 Bde, 1920-1944), Personalsachen (ca. 80 Bde, 1920-1944), Ausrüstung (14 Bde, 1919-1943); polizeiliche Maßnahmen und Ermittlungen, Allgemeines (12 Bde, 1894-1942, u. a. Spionageabwehr 1914-1944, Liste ausgebürgerter KPDund SPD-Funktionäre, 1937), Lohnkämpfe und Überwachung von Arbeitern (7 Bde, 1913-1941, u. a. Anordnungen der Staatspolizeistelle Magdeburg über Einlieferung in Arbeits- und Konzentrationslager), Überwachung politischer Vereinigungen und staatsfeindlicher Unternehmungen (7 Bde, 1930-1942, enthält auch Material zur NSDAP, 1929-1937), Einwohnerwehren, Selbstschutzorganisationen (1914-1939).

- Verteidigungsangelegenheiten, Kriegswirtschaft: Allgemeine Maßnahmen und Anordnungen (13 Bde, 1920-1945, darin: Behandlung des Eigentums von Angehörigen feindlicher Staaten und Juden, 1939-1944), Produktions- und Verbrauchsregelungen (ca. 50 Bde, 1939-1944), Kriegsleistungen, Arbeitsverhältnisse, Flüchtlingsfürsorge (13 Bde, 1939-1944, u. a. Einsatz von Fremdarbeitern und Kriegsgefangenen), Zusammenarbeit mit Kriegswirtschaftsdienststellen (18 Bde, 1936-1945, u. a. Besprechungen des Gauleiters Eggeling 1941-1942 als Reichsverteidigungskommissar, Unterhaltungskosten des Gaubefehlsstandes, Landeswirtschaftsamt), Luftschutz und Hilfsmaßnahmen (25 Bde, 1931-1945), Wehrdienst, Musterung, Aushebung (7 Bde, 1935-1945), Truppenmärsche und Manöver (3 Bde, 1931-1935), Verhältnisse der Militärpersonen (ca. 30 Bde, 19361945).

- Handel und Gewerbe, Arbeitsrecht: Allgemeines (ca. 50 Bde, 1826-1943, darin Reichstreuhänder der Arbeit Mitteldeutschland, 1933-1943, Bestimmungen für den Gewerbebetrieb der Juden, 1937-1942), Vierjahresplan (13 Bde, 1936-1940), Eichwesen (12 Bde, 1909-1942), Handels- und Gewerbeorganisation (19 Bde, 1899-1943), Kreditund Bankwesen, Börsen (4 Bde, 1925-1943), Messen, Märkte und Ausstellungen (13 Bde, 1876-1944), einzelne Handels- und Gewerbezweige (ca. 110 Bde, 1820-1944, darin: 3 Bde betr. Sitzungen des Verwaltungsausschusses des Landesarbeitsamtes Mitteldeutschland, 1931-1944, 15 Bde betr. Bekämpfung der Arbeitslosigkeit, 1933-1938). - Bauwesen und Verkehr, Arbeitsbeschaffung (45 Bde, 1932-1942), Reichs- und Landesplanung (18 Bde, 1928-1944), öffentliche und Privatbauten (ca. 50 Bde, 1834-1945, darin Luftschutzmaßnahmen auf dem Grundstück des Oberpräsidenten, 1932-1945), Wege- und Straßenbauten, Reichsautobahnen (21 Bde, 1828-1944), Wasserbausachen (11 Bde, 1898-1942), Eisenbahnen und Straßenbahnen im allgemeinen (ca. 20 Bde, 1876-1944) und Bau einzelner Strecken.

- Bergwerks-, Post-, Münz- und Lotteriesachen (25 Bde, 1819-1946).

- Land- und Wasserwirtschaft: Verwaltungs- und Unterstützungssachen (35 Bde, 18991941), Landarbeiter (4 Bde, 1919-1942), Auflösungen, Enteignungen (6 Bde, 18581944), Landwirtschaftskammer (12 Bde, 1923-1945), landwirtschaftliche Schulen und Vereine, Viehzucht, Feldwirtschaft und Gartenbau (ca. 75 Bde, 1900-1945), Weinbau (20 Bde, 1925-1945); Wasserwirtschaft im allgemeinen (ca. 60 Bde, 1894-1944), Hochwasserschutz, Talsperren (ca. 35 Bde, 1897-1945), Flußregulierungen, Meliorationen (ca. 50 Bde, 1887-1944), Domänen-, Forst- und Fischereisachen (25 Bde, 1883-1945). - Wohlfahrtspflege und Fürsorgewesen: Allgemeines (ca. 30 Bde, 1920-1944), milde Stiftungen, Heime (13 Bde, 1818-1944), Johanniterorden und Diakonissenanstalten (3 Bde, 1854-1938), Armen- und Krankenpflege (4 Bde, 1912-1944), Hilfsaktionen, Kollekten und Sammlungen (15 Bde, 1899-1945). 
- Vereinswesen: Gemeinnützige Unterstützungsvereine, Verleihung von Korporationsrechten (1929-1941), wirtschaftliche Vereine (ca. 20 Bde, 1893-1944), Beamten- und Berufsvereine (7 Bde, 1880-1943), monarchistische und nationalistische Vereine (19 Bde, 1884-1943, u. a. „Kraft durch Freude“, 1934-1943, NS-Frauenschaft, 1911-1937, NS-Studentenschaft, 1935-1942), Fürsorge- und Unterstützungsvereine (12 Bde, 18981943), wissenschaftliche und künstlerische Vereine (18 Bde, 1847-1943), Sportvereine (4 Bde, 1906-1943), kirchliche und religiöse Vereine (9 Bde, 1845-1941), Sittlichkeitsvereine (2 Bde, 1929-1941).

- Anstaltswesen: Sicherheits- und Erziehungsanstalten (5 Bde, 1832-1943), Krankenund Irrenanstalten (15 Bde, 1919-1944), Straf- und Besserungsanstalt Halle (18981939), Erziehungs-, Ausbildungs- und Versorgungsanstalten (ca. 40 Bde, 1824-1944, darin: Jüdisches Waisenhaus in Berlin, 1838-1940).

- Statistik, allgemeine und topographische Erhebungen, Bevölkerungs- und Ortsstatistik (9 Bde, 1883-1944), Gewerbe-, Krankenhaus- und Steuerstatistik (3 Bde, 19361944), Landwirtschaftsstatistik (8 Bde, 1855-1944), kriegswirtschaftliche und Brandstatistik (5 Bde, 1940-1944).

Die Überlieferung der Landeskulturabteilungen (Rep. C $20 \mathrm{~V}$ in der Außenstelle Wernigerode) ist nach Regierungsbezirken und Orten geordnet und stammt jeweils aus dem Zeitraum zwischen 1821 und 1952. Generalakten betreffen u. a. Behördenorganisation und Geschäftsbetrieb im allgemeinen (33 Bde, 1851-1951), Kultur- und Bodenämter (7 Bde, 1933-1950), Personalangelegenheiten (58 Bde, 1920-1950), Verwaltungsberichte und Jahresnachweisungen (4 Bde, 1926-1951), Siedlungswesen (44 Bde, 1933-1950) und Umlegungen (19 Bde, 1928-1950).

Lit.: GRUNDRISS zur deutschen Verwaltungsgeschichte 1815-1945. Reihe A, Bd 6: Provinz Sachsen.

\subsubsection{Provinzialverwaltung Sachsen, Merseburg $\quad$ MD, Rep. C 92}

Im Gesamtbestand aus der Zeit von 1841 bis 1946 sind u. a. folgende Akten aus der NS-Zeit überliefert, in der Landeshauptmann Kurt Otto die Verwaltung leitete:

- Zentralabteilung: Provinzialgesetzgebung und deren Ausführung (22 Bde, 18961943), Beamte und Geschäftsbetrieb (ca. 70 Bde, 1876-1943), Verkehr mit Bankinstituten (14 Bde, 1936-1946), Kassen- und Rechnungswesen (ca. 30 Bde, 1927-1946), Jahresberichte und allgemeine Übersichten (9 Bde, 1931-1943), Beteiligung an der allgemeinen Landesverwaltung (ca. 10 Bde, 1934-1944).

- Abteilung Z-Pers.: Allgemeine Angelegenheiten (ca. 50 Bde. 1894-1943). Zu den vorhandenen undatierten Personalakten sind „Untersuchungsakten gegen frühere Nazigegner" (24 Personen, überwiegend Pfleger in Landesheilanstalten), „Strafakten“ (6 Personen) und sonstige „Untersuchungsakten“ (6 Personen) nachgewiesen.

- Abteilung III: Provinzialkurheime, Landesfürsorgeverband (ca. 80 Bde, 1928-1946, überwiegend Einweisungs- und Entlassungsunterlagen), Festspiele Bad Lauchstädt (2 Bde, 1926-1948), Land- und Wasserwirtschaft (ca. 60 Bde, 1927-1945), Wasser-, Talsperrenbau (ca. 110 Bde, 1927-1946), Mitteldeutsche Hafen AG Halle (ca. 20 Bde, 1930-1944).

- Abteilung IV Straßenwesen: einzelne Baumaßnahmen (bis 1935), Bauten für die Flugplätze Halle, Leipzig, Magdeburg und Erfurt (ca. 20 Bde, 1936-1944).

- Abteilung VI Energiewirtschaft: Allgemeines (10 Bde, 1918-1944), Elektrizitätsversorgung (8 Bde, 1917-1945), Mitteldeutscher Bezirks- (4 Bde, 1932-1935) und 
Reichsverband (6 Bde, 1929-1944), Kapitalbeschaffung, Tarife (13 Bde, 19281946), Geschäftsberichte (7 Bde, 1929-1943), Personalien (3 Bde, 1937-1943), Kriegsmaßnahmen (9 Bde, 1935-1944), Gasversorgung, insbesondere Fernversorgung (14 Bde, 1925-1944), Angelegenheiten einzelner Elektrizitätsunternehmen.

Einen gesonderten Bestand bildet das Schriftgut des Provinzialrates (1870-1945, MD, Rep. 20 C II). Darin stammen aus der Zeit nach 1933 nur Akten über Allgemeine Verwaltungssachen mit Beschlußsammlung (23 Bde, 1923-1944), Kommunalsachen (2 Bde, 1903-1941), Schutz des Baumbestandes und der Uferwege (1930-1936).

\subsubsection{Oberpräsidium von Pommern, Stettin}

GW, Rep. 60; STE, Best. 73

Die Überlieferung im älteren Teilbestand in Greifswald endet durchweg 1934, so daß sich die Akten aus der Amtszeit des Oberpräsidenten Carl v. Halfern, der im Oktober 1933 ausschied und erst im Juli 1934 durch Gauleiter Franz Schwede-Coburg ersetzt wurde, auf wenige Unterlagen u. a. über Gemeindeverfassungs- und -finanzgesetz (1933-1934), Domänen- (2 Bde, 1911-1934) und Forstsachen (1920-1934), Anleihen (1927-1934), Provinz- und Kreisgrenzen (1928-1934), Gewerkschaften und Angestelltenverbände (1928-1934), Armenfürsorge im Regierungsbezirk Stettin (1920-1934), Erteilung von Heimatscheinen (1923-1934), Ausweisungen und Auslieferung (1926-1934), Kraftfahrzeugwesen (2 Bde, 1927-1934), Verwaltung der Irren-Anstalten (2 Bde, 19221934) beschränken.

Im Stettiner Teilbestand reichen viele Akten ebenfalls nur bis 1934. Darin ist vertreten die

- Allgemeine Abteilung mit Unterlagen u. a. über Deutsche Nothilfe (3 Bde), Landesarbeitsamt, Arbeitsbeschaffungsprogramm (14 Bde, 1933-1934), Reichstreuhänder der Arbeit (5 Bde, 1933-1934), Totenfeiern (1 Bd), Verwaltungsreform (2 Bde, 19331934), Organisation des Oberpräsidiums (11 Bde, 1933-1934), Schulwesen (1 Bd, 19331934), Besprechungen beim Oberpräsidenten (2 Bde, 1933-1934), Mitglieder des Regierungskollegiums und andere Personalangelegenheiten (17 Bde, 1932-1934), vorstädtische Kleinsiedlung (6 Bde, 1933-1934), Kommunalanleihen und andere Haushaltssachen (4 Bde, 1933-1934), Baupolizei (3 Bde, 1933-1934), Gewerbesachen (1 Bd), Messen und Märkte (4 Bde), Straßen und Reichsautobahnen (3 Bde, 1933-1934), Eisenbahn(3 Bde, 1933-1934) und Straßenverkehr, Rügendamm, Brücken (10 Bde, 1933-1934), Gesundheitswesen (18 Bde, 1933-1934), dabei Ärztliches Ehrengericht (3 Bde), Heilund Pflegeanstalten in Pommern (6 Bde, 1933-1934), tierärztliche Standesgerichte (3 Bde, 1933-1934).

Über die Grenze von 1934 hinaus gehen einige Akten über Ausländerpolizei, Ausweiswesen (6 Bde, 1933-1938) und Konsulate (13 Bde, 1939-1944) und Schriftgut aus der

- Landeskulturabteilung betr. allgemeine Verwaltungssachen (10 Bde, 1933-1944), Angestellte und Beamte (16 Bde, 1933-1944), u. a. Entlassung jüdischer Beamter (1 Bd. 1935-1943), Siedler und Umsiedler (10 Bde, 1935-1943), Renten, Landesrentenbank (18 Bde, 1935-1944), Neubildung deutschen Bauerntums (21 Bde, 1933-1943), Futtermittel, Obstbau und Fischerei (12 Bde, 1933-1943), Besitz der polnischen Minderheit (2 Bde, 1939-1944), Verzeichnis der großen Güter (1 Bd, o. D.), Ansiedlung (740 Bde, 1935-1944), jüdischer Landbesitz (14 Bde, 1938-1945), Meliorationen, Deiche, Reichslandkulturfonds (260 Bde, 1933-1944), Grundrenten (90 Bde, 1936-1944), 
Landeskulturarbeiten (9 Bde, 1937-1944), Streit- und Beschwerdesachen (8 Bde, 19381944), Entschuldung (62 Bde, 1933-1944).

Tätigkeitsberichte liegen vom Regierungsvizepräsidenten im Oberpräsidium Mackensen v. Astfeld, Beamten der Wehrwirtschaftsverwaltung, Landesplanung, Medizinalabteilung und dem Leiter der Preisbildungsstelle vor (BA KO, Best. Ost-Dok. 8 und 10 ).

Lit:: GRUNDRISS zur deutschen Verwaltungsgeschichte 1815-1945. Reihe A, Bd 3: Pommern.

\subsubsection{Provinzialverwaltung Pommern, Stettin GW, Rep. 54/1, 2}

Die aus der Zeit von 1933 bis 1945, als der Landeshauptmann Emil Mazuw zugleich Höherer SS- und Polizeiführer im Wehrkreis II war, überlieferten Akten der Hauptabteilung betreffen u. a. Geschäftsverteilung (1916-1940), Verfügungen (4 Bde, 19331942), die Verwaltungsakademie Pommern (1925-1943), Zahlungen an die Gauleitung für grenzpolitische Zwecke (1934-1942), Errichtung eines Bismarck-Denkmals (19081943) sowie eines Ehrenmals für die Gefallenen (1936-1941), Ausstellungen (19361944).

Der Hauptteil des Bestandes nach 1933 betrifft Kunst und Wissenschaft und stammt aus der Kulturabteilung (345 Bde, 1902-1947), darin u. a. Unterlagen der Landeskundlichen Forschungsstelle (2 Bde, 1912-1944), zur Auslagerung bzw. Beschädigung von Kulturgut (3 Bde, 1943/44), über das Institut für Vererbungs-Wissenschaft (19291943) und das Staatswissenschaftliche Seminar (1938-1945) der Universität Greifswald, Ahnenforschung und Sippenkunde (1941-1944), Forschungsstelle „Pommern in aller Welt" (1937-1943), Verein Pommersche Brauchkunst (3 Bde, 1938-1944), Naturschutzstelle (1940-1945), Pommersches Landesmuseum (5 Bde, 1925-1944), Pommernraum in der Nationalpolitischen Erziehungsanstalt Köslin (1938-1943), Landesbühne (6 Bde, 1926-1944), Gesellschaft von Freunden und Förderern der Universität Greifswald (4 Bde, 1918-1944), Grenzmärkische Gesellschaft zur Erforschung und Pflege der Heimat (1938-1944), Hochschule für Lehrerbildung in Lauenburg (1937-1942), Förderung des pommerschen Schriftums (1940-1943), Erhaltung ahnengeschichtlich wertvoller Bauten (1936-1940), Ausstellung „Der pommersche Soldat“ (1938-1946), Bilder großer Pommern (4 Bde, 1937-1945) und Ostpropaganda (1936-1945). Akten (Rep. 54/4) über Straßenbau der Landesbauämter Stralsund und Stettin enden 1941.

Einen eigenen Bestand bilden die Akten des Provinzialkonservators Pommern (GW, Rep. 54/2, ca. 650 Bde, 1912-1948) u. a. zum Wirtschaftsbauprogramm (19381939), zur Landesplanungsgemeinschaft Grenzmark (1936-1937), Denkmalpflegeberichte (3 Bde, 1935-1952), Zusammenarbeit mit der Beratungsstelle für Kriegerehrungen (1921-1938), ferner Naturschutz, Kunst- und Naturdenkmäler, technische Denkmäler, Glockenablieferung, Luftschutzmaßnahmen, Sicherstellung von Kunstgut, Kirchen- und Ortsgeschichte, Bestandsaufnahme kirchlichen Inventars, Buntmetallerfassung, Instandhaltung der Kirchen.

Auch in Stettin (Best. 183) befinden sich Akten der Provinzialverwaltung (442 Bde, 1900-1937), die jedoch als nicht archivwürdig gelten und deshalb nicht erschlossen sind.

\subsubsection{Oberpräsidium von Ostpreußen, Königsberg GStA, Rep. 2}

Der Bestand enthält nur Schriftgut, das bis Kriegsende vom Staatsarchiv Königsberg übernommen worden war und in der Regel 1933 oder vorher endet. Eine Ausnahme bilden lediglich einzelne Bände, die Organisation der Behörde (bis 1935), Verkehrswesen 
(bis 1934), die Landratsämter (bis 1935), Jugendpflege (bis 1934) und Arbeitsbeschaffungsmaßnahmen (bis 1934) betreffen.

Ob sich Akten dieser Provenienz in russischen Archiven befinden, ist nicht bekannt, in Polen ist lediglich ein älterer, nicht erschlossener Teilbestand (598 Bde, 1810-1936) in Allenstein nachgewiesen, auch besitzt möglicherweise das Instytut Zachodni Reste.

Ersatzüberlieferung ist in den Akten des Verfahrens gegen den Oberpräsidenten und Gauleiter Erich Koch vor dem Obersten Volksgericht der VR Polen enthalten (GKW), dem ein Ermittlungsverfahren durch die Anklagebehörde bei den Spruchgerichten für die britische Zone vorausging (Akten im BA KO, Best. Z 42). Aussagen über Koch und sein Verhalten 1945 enthalten auch Berichte, die Beamte des Oberpräsidiums, darunter der Vertreter des Oberpräsidenten und Dezernenten der Reichsverteidigungsabteilung, des Provinzialschulkollegiums, der Medizinal- und der Landeskulturabteilung, Preisbildungsstelle, Gewerbeaufsicht, der Generaldezernent für Siedlungswesen, Generalbevollmächtigte für Bauwesen und der Bevollmächtigte für Nahverkehr über ihre Tätigkeit geliefert haben (BA KO, Best. Ost-Dok. 8 und 10).

Lit.: GRUNDRISS zur deutschen Verwaltungsgeschichte 1815-1945. Reihe A, Bd 1: Ost- und Westpreußen.

\subsubsection{Provinzialverwaltung Ostpreußen, Königsberg}

In den Akten des Oberpräsidiums im GStA sind Haushaltssatzung und Haushaltspläne überliefert (14 Bde, 1938-1944), im BA KO Berichte des Landeshauptmanns v. Wedelstaedt und von Mitarbeitern der Straßenbau-, Fürsorge- und Medizinalabteilung (Best. Ost-Dok. 8 und 10).

\subsubsection{Oberpräsidium der Provinz (Nieder)Schlesien, Breslau}

BRE, Best. 18

Die Zuständigkeit des Oberpräsidiums für ganz Schlesien wurde 1919 auf die niederschlesischen Regierungsbezirke Breslau und Liegnitz beschränkt, ab 1938 unterstand ihm jedoch erneut auch der oberschlesische Regierungsbezirk Oppeln und ab Herbst 1939 der Regierungsbezirk Kattowitz, die 1941 wieder zu einer Provinz Oberschlesien vereinigt wurden. In dem bis in das 18. Jahrhundert zurückreichenden Bestand ist die gesamte Überlieferung vereinigt, so da $B$ zwischen 1938 und 1941 geführte Akten auch Angelegenheiten Oberschlesiens betreffen können, doch ist insgesamt aus der Zeit nach 1933, in der bis zur Teilung der Gauleiter Josef Wagner, dann der frühere Staatssekretär im Propagandaministerium Gauleiter Karl Hanke Oberpräsidenten waren, nur wenig erhalten geblieben.

Aus der Allgemeinen Abteilung sind nur einzelne Akten über die Kommunalaufsicht bis 1934, über die Wirtschaft im allgemeinen, vor allem Lageberichte (15 Bde, 19351942, insbesondere über Bergbau und Rüstungsindustrie), über den Reichstreuhänder der Arbeit (1935-1941, mit Statistiken) und das Landeswirtschaftsamt (4 Bde, 19391943) vorhanden. Umfangreicher ist allerdings die Überlieferung der Preisbildungsstelle (318 Bde, 1935-1945) mit Akten über Aufbau, Organisation und personelle Besetzung (5 Bde), Geschäftsverteilung (5 Bde), Preisüberwachung, Anwendung des $\S 22$ der Kriegswirtschaftsverordnung im Handel vor allem mit Nahrungs- und Genußmitteln, in der Holz- und Forstwirtschaft, Bauwirtschaft, Leichtindustrie.

Akten über Polizeiangelegenheiten (9 Bde, 1931-1944) betreffen u. a. die Eindeutschung von Familiennamen, die Behandlung von Häftlingen mit Listen von Personen, die durch die Gestapo festgenommen wurden und in Konzentrationslager überführt wurden, 
und Kriegsgefangenen, die Fahndung nach Flüchtigen. In Unterlagen über Straßenbau (2 Bde, 1935-1942) ist u. a. der Bau der Sudetenstraße und der Reichsautobahn dokumentiert. In einer Sammlung von Erlassen (dabei auch betr. Abwehr von Greuelpropaganda über Vorgänge in den besetzten Ostgebieten 1941) sind insbesondere der Reichsführer SS und Chef der Deutschen Polizei und der Beauftragte für den Vierjahresplan vertreten (3 Bde, 1936-1941). Von den Übersichten und Meldeblättern der Gestapo über Schutzhäftlinge und den Erlassen für die Polizei ist im BA P (PL-029) ein Mikrofilm vorhanden, im BA KO (Kl. Erw. 703) eine Sammlung von Bekanntmachungen Hankes aus den Kämpfen um Breslau (Januar-März 1945).

Lit.: GRUNDRISS zur deutschen Verwaltungsgeschichte 1815-1945. Reihe A, Bd 4: Schlesien.

\subsubsection{Provinzialverwaltung (Nieder)Schlesien, Breslau BRE, Best. 130}

Der relativ vollständige Bestand (9290 Bde, 1758-1945) enthält aus der Zeit ab 1933 (ca. 5700 Bde) eine Sammlung von Rundschreiben und Verordnungen auch des Oberpräsidenten (22 Bde, 1934-1944) und Schriftgut aus folgenden Organisationseinheiten bzw. Kompetenzen:

- Zentralbüro des Landeshauptmanns (zuletzt Adams): Erlasse und andere Unterlagen zur Organisation (7 Bde, 1931-1944), Akten über Haushalts- und andere Finanz- und Kassensachen (417 Bde, meist 1927-1944), vor allem über Beteiligungen und Darlehen (u. a. für Arbeitsbeschaffungsmaßnahmen), den Anschluß von Gemeinden und Körperschaften an die Provinzialfürsorgeeinrichtungen (147 Bde, 1924-1938) und über die Volkstumsarbeit durch Zusammenarbeit mit und Unterstützung von Verbänden und Instituten, darunter Bund Deutscher Osten, seine Veranstaltungen und Publikationen (138 Bde, 1922-1944, überwiegend nach 1937, dabei Nachrichten über die Lage im tschechischen Teil Schlesiens), Deutsche Stiftung, Publikationsstelle Berlin-Dahlem (27 Bde, 1922-1939), Nordische Gesellschaft (21 Bde, 1934-1944), Wirtschaftspolitische Gesellschaft und Arbeitsgemeinschaft für Wirtschaftsausbau (25 Bde, 1927-1945), in geringerem Umfang Vereinigte Verbände heimattreuer Oberschlesier, Deutsch-Ausländischer Akademiker-Klub, Verband der Großgrundbesitzer in Schlesien, Baltisches Institut, Schlesische Gesellschaft für Volkskunde, Historische Kommission für Schlesien, mit Sachakten u. a. über die gemeinsame Propaganda der vier Ostprovinzen (5 Bde, 1930-1940) und die Revision der Ostgrenzen (5 Bde, 1930-1938).

- Kulturabteilung: Rundverfügungen (5 Bde, 1937-1945), Museumsangelegenheiten und Kunstpflege (202 Bde, 1878-1944, davon 154 über das Landesamt für kulturgeschichtliche Bodenaltertümer bzw. für Vorgeschichte mit Nachweisen einzelner Funde, 1900-1940), Kunstdenkmalschutz durch den Provinzialkonservator (35 Bde, 19021943), Naturdenkmalpflege und -schutz, vor allem von Baumbeständen (138 Bde, 19081941), Tierschutz (4 Bde), Förderung von Kunst und Wissenschaft (240 Bde, 19131945), u. a. des Schlesischen Bundes für Heimatschutz (105 Bde), des Landeshauses und seiner Veröffentlichungen mit Forschungsstelle „Schlesier in aller Welt" (29 Bde), des Osteuropa-Instituts (3 Bde, 1929-1944), des Balneologischen Reichsinstituts (19351944), von Theatern (9 Bde), durch die Landesbildstelle (3 Bde) und Verleihung des Schlesischen Literaturpreises, von Kunst- und Musikpreisen (3 Bde, 1937-1942).

- Statistisches Amt: Wirtschafts-, Arbeitseinsatz-, Fremdenverkehrs-, Landwirtschafts-, Kultur- und Bevölkerungsstatistik (148 Bde, 1931-1944, dabei 5 Bde betr. kriegswirtschaftliche Kräftebilanz 1943-1944). 
- Pressestelle (28 Bde, 1938-1944), u. a. Zeitungsausschnitte über nationale Minderheiten in Deutschland und im Ausland.

- Medizinalabteilung: Aufsicht über die Heil- und Pflegeanstalten Brieg, Bunzlau, Kreuzburg, Leubus, Lüben (183 Bde, 1785-1944, meist 19. Jahrhundert, mit einzelnen Unterlagen über Belegung und Todesfälle bis 1942) und Hebammensachen (50 Bde, überwiegend ab 1941).

- Fürsorgeabteilung: Fürsorge für Geisteskranke (77 Bde, 1924-1942), u. a. Durchführung des Erbgesundheitsgesetzes (3 Bde, 1933-1935), Kastration von Sexualstraftätern (3 Bde, 1931-1943), Behandlung von Juden (2 Bde, 1938-1943), Verlegung in Tötungsanstalten (5 Bde, 1939-1944), Belegung einzelner Anstalten für Krüppel, Blinde und Taubstumme (22 Bde, 1925-1942), Gewährung von Darlehen aus dem Jugendpflegefonds, u. a. für Jugendherbergen und Sportanlagen (20 Bde, 1925-1945).

- Tiefbauabteilung: Bau von Straßen, Brücken und Kleinbahnen (86 Bde, davon 19 Bde mit Erlassen des Generalinspektors für das deutsche Straßenwesen 1933-1942).

Während aus der Zuständigkeit für den Wasserbau umfangreiche Akten (762 Bde) und der Flußkataster, für das Vermessungswesen ein größerer Rest (93 Bde) überliefert sind, gibt es über Hochbau nur wenig (12 Bde), über die Förderung der Landwirtschaft gar nichts.

Die im Bestand enthaltenen Akten des Landesjugendamtes (100 Bde, 1924-1944) betreffen neben einigen Geheimsachen (1941-1944) vor allem die Unterbringung von Jugendlichen in Bad Altheiden, Jannowitz und anderen Heimen, diejenigen des Landeswohlfahrtsamtes (288 Bde, 1921-1944) dokumentieren hauptsächlich die Durchführung des Schwerbehindertengesetzes bei einzelnen Firmen und Behörden, enthalten aber auch Unterlagen über die Umschulung ,alter Kämpfer“ der NSDAP (1938-1944), Wehrdienstbeschädigungen (30 Bde, 1943-1945), Tbc-Hilfe (45 Bde), die Zedlitz- und andere Stiftungen (34 Bde).

Auf Mikrofilmen sind im BA P (23 Filme von 60 Bden, Best. PL-044) Unterlagen über den Bund Deutscher Osten, das Osteuropa-Institut, die Historische Kommission und die Volkstumspolitik und über jüdische Geisteskranke, Umwandlung von Krankenanstalten in Reservelazarette, Verlegung von Geisteskranken in das Generalgouvernement, ferner das Protokoll einer Tagung in Sonthofen 1944 über bauliche Unterhaltung des Straßennetzes unter Kriegsbedingungen vorhanden.

\subsubsection{Oberpräsidium von Oberschlesien (bis 1938), Oppeln}

OP, Best. 1

Im Bestand (1242 Bde, 1837-1937), der auch Oberschlesien betreffende Akten des Oberpräsidiums von Schlesien vor 1919 enthält, ist die Überlieferung aus den vier Jahren von 1933 bis zur Aufhebung, in denen der niederschlesische Oberpräsident und Gauleiter Wagner das Amt bereits in Personalunion verwaltete, nur wenig in folgender Gliederung vorhanden:

- Allgemeines, Organisation (5 Bde, 1931-1934) und Politik (7 Bde, 1933-1937, dabei Beschwerden über Unkenntnis über die Verhältnisse Oberschlesiens 1933-1934, Folgen des Versailler Vertrags), Landjahr (5 Bde, 1933-1934).

- Abgabewesen, Versicherungen, u. a. Oberschlesische Feuersozietät, Landesbank O/S (7 Bde, 1933-1937).

- Volkstums- und Minderheitenfragen: Deutsches Konsulat Kattowitz (1930-1936), Deutsches Minderheitsamt (3 Bde, 1933-1937), polnische Minderheit und Bewegung 
(5 Bde, 1933-1937), Zweisprachigkeit (4 Bde, 1933-1937), Ausschreitungen Deutscher gegen Polen (8 Bde, 1932-1937, u. a. Wahlterror, Beschwerden beim Völkerbund) und von Polen gegen Deutsche (2 Bde 1931-1937), Deutschtum in Polen (2 Bde, 19301938), deutsche Schulen in Ostoberschlesien (1931-1937), polnische Schulen im deutschen Gebiet (12 Bde, 1933-1937), Bund für das Deutschtum in Posen und Pommern (1934-1937), Maßnahmen gegen die Deutschen in Polen (4 Bde, 1930-1937), polnische Nationalfeiern (2 Bde, 1932-1937), ausländische Äußerungen zur oberschlesischen Frage (2 Bde, 1933), Erhaltung des Deutschtums in Ostoberschlesien (2 Bde, 19311937), polnische Parteien und Vereine (25 Bde, 1931-1937, u. a. Katholische Volkspartei 1933), Jugendbewegung, Sport-, Gesang-, Arbeiter-, Landwirtschafts- und Veteranenvereine, Bund der Schlesier (2 Bde, 1931-1937), polnische Literatur, Rundfunk, Theater (6 Bde, 1931-1937), polnische Presse (3 Bde, 1931-1937), deutsche Presse in Polen (4 Bde, 1931-1937), Minderheitenschutz durch Genfer Vertrag, gemischte Kommissionen, Schiedsgerichte (18 Bde, 1931-1937, dabei auch Schutz für Juden), einzelne Beschwerden von Polen (463 Bde, 1933-1937), Deutschtum in der Tschechoslowakei (4 Bde, 1931-1937), deutsch-polnische Wirtschaftsabkommen (11 Bde, 1931-1937).

- Polizei und öffentliche Sicherheit: KPD (6 Bde, 1931-1933), nationale Organisationen, u. a. Verband heimattreuer Oberschlesier, Volksbund, Selbstschutz, Stahlhelm (8 Bde, 1933-1937), Sicherheits-, politische Polizei (3 Bde, 1933-1936), Reichswehr (1930-1936), Republikschutzgesetz (2 Bde, 1933-1937), Sprengstoffverbrechen (19311933), Ausweisung von Ausländern (1933-1937), Spionageabwehr durch Überwachung von Brieftaubenhaltern (1933), Waffenbesitz, Entwaffnung (3 Bde, 1933-1934), Grenzund Kommunalangelegenheiten: Kreisbeamte (5 Bde, 1933-1934).

- Landwirtschaft: Allgemeines (1933-1934), Rentengüter (1933), Grundstücksverkehr (2 Bde, 1933), Siedlungswesen (5 Bde, 1933-1934), Erbhofrecht (1933-1934), Umschuldungen (3 Bde, 1933-1934), Verordnung zur Sicherung der Ernte (1933).

Nur jeweils ein einzelner Band betrifft Ortsnamenänderungen (1933-1934), naturgeschichtliche Altertümer (1933), die Provinzialstelle für Naturdenkmäler (1933), die Unterhaltung öffentlicher Bauten (1934), Unwetterschutz (1933) und Fürsorgeangelegenheiten (1933).

Von Akten über die Grenzziehung zwischen Polen und Deutschland, Verfolgung der Deutschen in Ostoberschlesien, über Grenz- und Auslandsdeutschtum sind Mikrofilme im BA P vorhanden (6 von 9 Bden, Best. PL-013).

Lit:: GRUNDRISS zur deutschen Verwaltungsgeschichte 1815-1945. Reihe A, Bd 4: Schlesien.

\subsubsection{Oberpräsidium von Oberschlesien (1941-1945), Kattowitz}

KAT, Best. 117/I; ZDM MO, Best. 1232

Zu der am 1. April 1941 unter dem Oberpräsidenten und Gauleiter Fritz Bracht gebildeten Provinz gehörten außer dem Regierungsbezirk Oppeln und den bis 1920 bzw. 1922 preußischen Teilen des Regierungsbezirks Kattowitz auch die polnischen Kreise Bendzin (Bendsburg), Bielsko (Bielitz), Blachownia (Blachstädt, aus Teilen der Kreise Zawiercie und Tschenstochau), Chrzanow (Krenau), Olkusz (Ilkenau), Sosnowiec (Sosnowitz), Zawiercie (Warthenau), Zywiec (Saybusch) und der zum Teil 1938 von Polen annektierte tschechische Kreis Teschen (Cieszyn). Der gut erhaltene Kattowitzer Bestand (2306 Bde) enthält Schriftgut (zum Teil mit Vorakten des Oberpräsidiums in Oppeln) folgender Organisationseinheiten:

- Abteilung I, Allgemeine Abteilung (816 Bde): 
- - Allgemeine Anordnungen für die eingegliederten Gebiete (4 Bde, 1939-1943), Erlasse des Oberpräsidenten (4 Bde, 1939-1945), Ausweichunterkunft Bautzen (1945), Reichsleistungsgesetz, Polizeiverordnungen, Ortsnamenänderungen (10 Bde, 19411944), Einführung von Reichsrecht (6 Bde, 1939-1941), Steuerrecht im Sudetenland (2 Bde, 1939), Versammlungs- und Feiertagsrecht (5 Bde, 1939-1941), Grenzangelegenheiten (7 Bde, 1941-1944), Personal- und Besoldungssachen (14 Bde, 1939-1944), Verwaltungsreform (10 Bde, 1941-1944).

- - Öffentliche Sicherheit: Schutz des Gauleiters (2 Bde, 1942), Ordnungspolizei (11 Bde, 1941-1944), deren Ausbildung (10 Bde, 1939-1943), Tagesmeldungen, Einziehung staats- und volksfeindlichen Vermögens (1 Bd, 1943), polizeiliche Entscheidungen (6 Bde, 1943-1945), Totaler Krieg (9 Bde, 1944), Schutz der Bevölkerung vor entwichenen Kriegsgefangenen (1942-1943), Paßwesen, Wanderungsstatistik, Grenzlandbeihilfe (10 Bde, 1939-1944).

- - Volkstumsangelegenheiten: Allgemeiner Schriftwechsel, Listen von Volksdeutschen (13 Bde, 1941-1944), Namensänderungen, Prüfung der Besitzverhältnisse (15 Bde, 1941-1944), Deutschtumspflege (9 Bde, 1939-1942).

- - Zivile Reichsverteidigung: Arbeitseinsatz (5 Bde, 1943), Luftschutz, Gaueinsatzstab (32 Bde, 1941-1944), Bombenschäden (4 Bde, 1941-1944), Hilfe für Luftkriegsgebiete, u. a. Düsseldorf, Hamburg, Westfalen-Süd (4 Bde, 1944), Katastrophenschutz, Feuerwehr (18 Bde, 1941-1944).

- - Schul- (12 Bde, 1941-1942) und kirchliche Angelegenheiten: Kirchenbesitz, Rechte der Diözese (32 Bde, 1941-1944), Friedhofsangelegenheiten (13 Bde, 19411944), Beschlagnahme von Kircheneigentum, Klöstern und Heimen (12 Bde, 19411943), Vereine und Unterricht (15 Bde, 1941-1944, u. a. Entfernung der Kruzifixe in den Schulen 1941), kirchliche Feiern und Feiertage (5 Bde, 1941-1943), Kirchensteuer und Pfarrämter, straffällige Pfarrer (21 Bde, 1939-1942).

- - Gemeindeangelegenheiten: Sparkassen (8 Bde, 1941-1944), polnische Banken (2 Bde, 1940-1944), Gemeindesteuern, Kfz-Steuer (4 Bde, 1941-1942), Personalangelegenheiten, Abordnung von Bürgermeistern und Beamten (5 Bde, 1940-1944).

- - Wirtschaft und Verkehr: Vordrucke, Zusammenarbeit mit anderen Dienststellen (12 Bde, 1939-1944, u. a. mit Haupttreuhandstelle Ost, Gau- und Kreiswirtschaftsberatern), Transportwesen (6 Bde, 1941-1944), Handel, Ladenschluß (4 Bde, 1941-1944), Fremdarbeiter (5 Bde, 1941-1944), Sportaufsicht (1942-1944), Deutsches Rotes Kreuz (1942-1944).

- - Preisbildung und -überwachung: Allgemeines, Kriegswirtschaftsstab, preispolitische Lageberichte (27 Bde, 1941-1944), Preisstraf- (Gerichts- und Ordnungs-) Verfahren (15 Bde, 1939-1944), Preispolitik, allgemeinwirtschaftliche Fragen (10 Bde, 1944), Tarifordnungen für die einzelnen Wirtschaftszweige (32 Bde, 1942-1944), Gewinnabschöpfung (21 Bde, 1942-1944), Preisverstöße kriegswichtiger Betriebe in Kattowitz, Elsaß, Luxemburg, Böhmen und Mähren, Generalgouvernement, Belgien (8 Bde, 19401944), Preisbildung u. a. im Handwerk und Handel (23 Bde, 1941-1944), für landwirtschaftliche Erzeugnisse (12 Bde, 1941-1944), im Gaststättengewerbe (12 Bde, 19411944), Bauwirtschaft (10 Bde, 1941-1944), Schwerindustrie (20 Bde, 1941-1944), beim Verkauf von Großbetrieben, u. a. Hütten und Bergwerken (90 Bde, 1944), Mieten und Pachten für Betriebe und Einrichtungen (10 Bde, 1939-1943), Kanal- und Müllabfuhrgebühren (5 Bde, 1941-1944).

- - Kulturelle Angelegenheiten: Heimatpflege, Bibliotheken, Denkmalpflege (14 Bde, 1941-1944), Schlesisches Institut (1939-1940). 
- Abteilung II, Schulwesen: nur Verfügungen und Rundschreiben (4 Bde, 1942), Erziehungswesen im Bezirk Oppeln, Ausbau der deutschen Schulen, Personalfragen (4 Bde, 1943-1944).

- Abteilung III, Landeskulturabteilung (1310 Bde): Siedlungspolitik (449 Bde, 19311941), Finanzierung von neuen Siedlungsstellen (16 Bde, 1933-1941), Reichssiedlungsstatistik für den Bezirk Oppeln (1935-1939), Agrarpolitik (15 Bde, 1939-1940), einzelne Siedlungen (32 Bde, 1935), Ansiedlung von Erwerbslosen auch in Niederschlesien (21 Bde, 1931-1941), Kredite und Veräußerungsgenehmigungen (93 Bde, 1933-1942, dabei Einsatz des jüdischen Vermögens in der Herrschaft Tost 1939-1940), allgemeine Siedlungspolitik (440 Bde, 1933-1941), Oberschlesische Landgesellschaft (5 Bde, 19331935), Personalien des vermessungstechnischen Dienstes (11 Bde, 1941-1944), Besiedlung von Domänen, Umsiedlung (42 Bde, 1935-1944, u. a. Einziehung von Grundbesitz von Polen 1941-1944), Umsiedlungskredite, Beihilfen für Siedler, Altsiedlerhilfe (8 Bde, 1940-1942), Siedlungsbauten und Stützpunktgüter (62 Bde, 1939-1943, u. a. auf jüdischem Grundbesitz 1941-1943), Reichsbodenkulturfonds (25 Bde, 1939-1944), Industrieschäden (5 Bde, 1941-1945), Wasserverbandsspruchverfahren (11 Bde, 19431944), Grundstückverkehr (5 Bde, 1941-1944), Umsiedlung und Siedlung in den einzelnen Kreisen (325 Bde, 1941-1944).

- Abteilung V, Medizinalabteilung: Apothekenwesen (5 Bde, 1941-1944), Hebammen und andere Heilhilfsberufe (8 Bde, 1941-1944), Zahnärzte (6 Bde, 1941-1943), Heilpraktiker (1941-1944), Unterbringung von Fremdarbeitern in Lagern (4 Bde, 1942-1944), Hygienemaßnahmen (13 Bde, 1942-1944), Bevölkerungspolitik, Schulhygiene, Schutz der Jugend, Volkspfleger (13 Bde, 1941-1944, dabei Erbgesundheitsgesetz 1941-1944), Nachweis von Infektionskrankheiten in den einzelnen Kreisen (9 Bde, 1941-1944), Jahresgesundheitsberichte (8 Bde, 1941-1944).

Die im BA P auf Mikrofilm vorhandenen Akten (9 Filme von 32 Bden, Best. PL-123) betreffen vor allem die Tätigkeit der Polizei (Sammlungen von Erlassen, Befehlsblättern, Fahndungsausschreiben, auch Lageberichte der Regierungspräsidenten), ferner Einsatz und Behandlung von Fremdarbeitern in der Industrie, den Verkauf größerer Industriebetriebe und Fragen des Gesundheitswesens, Kopien im BA KO (Best. Ost-Dok. 13) stammen aus den Akten des Strafverfahrens (GKW) gegen den Vertreter des Oberpräsidenten, Regierungspräsident Dr. Faust.

Der Moskauer Teilbestand (205 Bde, 1940-1945) enthält vornehmlich Akten über die Verleihung der deutschen Staatsangehörigkeit an Volksdeutsche, insbesondere im Wehrdienst, durch die Ausschüsse zur Durchführung der Deutschen Volksliste in Kattowitz und Oppeln (49 Bde, 1941-1945) und über Kirchensachen im allgemeinen (18 Bde), kirchliches Vermögen (Friedhöfe, Gebäude, Steuern und Kollekten, 24 Bde), dabei auch die Beschlagnahme von Klöstern (6 Bde, 1941), katholische Geistliche (17 Bde, u. a. Vorwürfe, Befreiung vom Wehrdienst), Kirchenbücher, Kindergärten (5 Bde, 19411945), Seelsorge bei Umsiedlern. Weniger umfangreich sind Akten über den Arbeitseinsatz von Kriegsgefangenen, Fremdarbeitern und Umsiedlern (11 Bde), Uk-Stellungen (17 Bde), Feuerschutzpolizei (6 Bde), Haushalt und Besoldung (16 Bde, u. a. der Polizei 1939-1942), dabei Mittel für NS-Propaganda, zur Förderung des Fremdenverkehrs und für kunstgeschichtliche Forschungen, mit Listen von Beamten und ihrer Bezüge, ferner über Gnadengesuche zum Tode verurteilter Polen und Juden (1942-1944). Lediglich einzelne Vorgänge dokumentieren die Organisation der Behörde (1942), Eheschließungen mit Ausländern (1941-1943), Grenzziehung zum Generalgouvernement, Kriegsschäden 
in Breslau und Oppeln, Luftschutz, Polenstraflager, die Folgen des 20. Juli 1944, Bauwirtschaft, Verkehr, Beschlagnahme polnischen und jüdischen Eigentums (Listen 1944) und Statistik.

Lit.: GRUNDRISS zur deutschen Verwaltungsgeschichte 1815-1945. Reihe A, Bd 4: Schlesien. - GROBELNY: Prameny k dejinam Ceskoslovenska za nazisticke okupace v Statnim archivu w Katovicich. 1966.

\subsubsection{Provinzialverwaltung Oberschlesien, Kattowitz KAT, Best. 118/I}

Während aus der oberschlesischen Provinzialverwaltung bis 1938 nur Splitter und nach Kattowitz übernommene Vorakten überliefert zu sein scheinen (3 Bde, OP, Best. 4, betr. Landesfrauenklinik, Unfälle und Verein Oder-Elbe-Kanal), bilden die nach der Neubildung der Provinz ab 1942 unter Landeshauptmann Katy geführten Akten einen umfangreichen Bestand (7121 Bde) in folgender Gliederung:

- I Allgemeine Abteilung (2751 Bde):

- - Organisation, Geschäftsverteilung, Verfügungen, Verordnungen, Urkundenregister (61 Bde, 1934-1945), Niederschriften über Besprechungen, Haushaltspläne (29 Bde, 1939-1942, dabei Korrespondenz mit dem Grenzschutzkommando 3).

- - Aufsicht über Provinzialinstitute (ca. 150 Bde), u. a. Landesamt für Volkskunde, Museen, Bibliotheken (15 Bde, 1934-1944), Versicherungen, Landesbildstelle, Wirtschaftsverwaltungen (31 Bde, 1934-1944), Kliniken, Landeserziehungsheime (28 Bde, 1940-1943), Heil- und Unterrichtsanstalt Istebna (4 Bde, 1939-1943), Landesmusikschule Kattowitz (5 Bde, 1939-1941), Schlesisches Akademikerhaus Krakau (1939), Provinzialkonservator in Oppeln (2 Bde, 1944), Landesarbeitsanstalt Kreuzburg, Landesheil- und -pflegeanstalten Loben (1944) und Tost (1939-1941) und andere Erziehungs-, Heil- und Pflegeanstalten, Schloß Weichsel (12 Bde, 1939-1943), Versicherungen und Krankenkassen (32 Bde, 1939-1943), Schloß Loben (3 Bde, 1943-1944); Grundbesitz (42 Bde, 1942-1944), Gutsverwaltungen (23 Bde, 1942-1944, dabei Anwerbung von Fremdarbeitern für die Landeserziehungsanstalt Grottkau, 1943-1944), Schloßgrundstücke, Güter und Mühlen (52 Bde, 1941-1944).

- - Straßenbau und Aufsicht über Landesstraßenämter (30 Bde, 1941-1943), Bau von Straßen, Brücken, Tunneln, Zusammenarbeit mit dem Wasserstraßenamt (33 Bde, 19391944).

- - Amt für Wohnungsfragen, vor allem Verwaltung von Dienstwohnungen (11 Bde, 1941-1944), Personalangelegenheiten (19 Bde, 1939-1943).

- - Schulwesen im allgemeinen, Pflegeeinrichtungen für Invaliden und andere Pflegeeinrichtungen (373 Bde, 1939-1944).

- - Liquidierung des Schlesischen Schatzes (97 Bde, 1940-1943), Vorkriegsforderungen (47 Bde, 1942-1944, u. a. der Fa. Carl Zeiss Jena).

- - Veräußerung einzelner Betriebe und Objekte (210 Bde, 1941-1944).

- Abteilung II - Finanzen:

- - Allgemeines, Bilanzen, Haushaltspläne, Hauptbücher, Aufnahme, Verwaltung und Gewährung von Darlehen und Krediten, u. a. an Klein- und Mittelbetriebe, Vermögensübersichten, Grundvermögen (495 Bde, 1939-1945).

- - Verwaltung von Immobilien, Kauf und Verkauf, Steinbrüche, Mieten, Neubauund Arbeiterkolonien (37 Bde, 1941-1944), Abrechnungsbücher über Grundstücke (375 Bde, 1941-1943) und für Arbeiterkolonien (102 Bde, 1942-1944). 
- - Landeshauptkasse: Vermögens- (32 Bde, 1943-1944) und Liegenschaftsrechnungen, Bilanzen, Straßenbaurücklage, Gesamtschuldennachweis, Gehaltszahlungen (293 Bde, 1941-1944).

- - Rechnungsprüfungsamt: Umzug der Provinzialverwaltung von Oppeln nach Breslau (1938-1939), Verfügungen, Rechnungsprüfung in Einzelfällen (243 Bde, 19381944) u. a. der Landesheilanstalten Kreuzburg und Tost (2 Bde, 1933-1935), anderer Heime und Anstalten.

- Abteilung Kultur und Kunst (661 Bde, 1923-1944): u. a. Aufnahme von Kulturdenkmälern, Archivangelegenheiten (2 Bde, 1934-1944), Landesamt für Vorgeschichte Breslau, Museen, Heimatzeitschriften, Landestheater, Künstlerbund Oberschlesien, Gedenkstätte Annaberg, Heimatvereine, Stiftung O/S, Verkauf und Ankauf von Kulturgut, Vereinigung Schlesischer Bund, Eichendorffgedenktage (4 Bde, 1941-1942), Ausstellungen.

- Abteilung Wirtschaft und Industrie (306 Bde, 1935-1944): u. a. Verkehr mit Wirtschafts- und Industriegruppen, Aufsichtsratssitzungen, Kraftwerke, Quartals- und Monatsfinanzberichte der Behörde, Eröffnungsbilanzen einzelner Betriebe (u. a. kommunale Kraftwerke, 35 Bde, 1943-1944), Prüfung der Jahresabschlüsse in ehemaligen polnischen Betrieben.

- Abteilung Sozialfürsorge (5 Bde, 1941-1944): Landesfürsorgeverband, Vereine zur Tuberkulosebekämpfung.

- Abteilung Jugendfürsorge (Landesjugendamt):

- Allgemeines, Erlasse, Organisation (13 Bde, 1941-1944), Zusammenarbeit mit NSV, Landessportamt, Vordrucke (20 Bde), Schulung von Volkspflegern (21 Bde, 19391941).

- - Jugendherbergen, Heime und Anstalten (70 Bde, 1940-1944), Waisenhäuser (35 Bde, 1941-1944), Einzelfälle der Heimunterbringung (30 Bde, 1941-1945), Einweisungen zur psychiatrischen Untersuchung in die Anstalt Loben (50 Bde, 1941-1944), örtliche Erholungsheime, Schulkinderspeisung (180 Bde, 1933-1944).

- - Gewährung von Studiendarlehen (584 Bde, 1940-1944), sonstige Begabtenförderung (41 Bde, 1941-1944), Vorschulwesen (5 Bde, 1942-1944).

- - Bestellung von Vormündern, Sammelvormundschaft des Pastors Zils (19 Bde, 1942, u. a. Antrag einer Mutter auf Entlassung ihres Sohnes von IG Farben Auschwitz 1943-1944), freiwillige Erziehungshilfe (20 Bde, 1942-1944).

- - Jugendarrest (2 Bde, 1942-1944), Einweisung in Jugendschutzlager (22 Bde, 19431945), speziell in das Jugendschutzlager Litzmannstadt (284 Bde, 1943), Fürsorgeerziehung im allgemeinen, Haushaltspläne, Konferenzen, Jahresberichte, Statistiken (31 Bde, 1941-1944) und Einzelfälle (23 Bde, 1942-1944), Durchführung des Erbgesundheitsgesetzes bei Zöglingen (1933-1938), Fürsorgeerziehung in kirchlichen Anstalten (30 Bde, 1941-1943), Haushaltspläne der einzelnen Heime (31 Bde, 1942-1944, u. a. außergewöhnliche Vorfälle in der Anstalt Teschen 1943-1944), Arbeitserziehung, Einzelfälle (20 Bde, 1943-1944).

- - Sportförderung durch Landessportbund (44 Bde, 1942-1944) und Kreisverbände (9 Bde, 1942-1944). 


\section{$1.4 \quad$ Behörden für auswärtige Angelegenheiten}

\subsubsection{E Auswärtiges Amt}

ZDM MO, Best. 1357

Den Hauptteil des Bestandes (350 Bde, 1816-1945) bilden Akten der Rechtsabteilung über die Abwicklung der ehemaligen diplomatischen und konsularischen Vertretungen Österreichs, der Tschechoslowakei, Polens und anderer Länder (83 Bde, 1938-1945). Größeren Umfang haben ferner Unterlagen über Deutsche in der Sowjetunion, ihre Unterstützung vor allem durch die Organisation „Brüder in Not“ (25 Bde, 1930-1944), ihre Verfolgung durch sowjetische Behörden (8 Bde, 1934-1941), ihre Überprüfung bei Rückkehr nach Deutschland (15 Bde, 1919-1942) wie auch von Rückwanderern aus Polen, den USA, Frankreich und anderen Ländern (48 Bde, 1933-1941) und über die Aufdeckung eines österreichischen Spionagezentrums in Berlin (28 Bde, 1934-1938). Nur einzelne Vorgänge betreffen Organisation und Personalangelegenheiten (1926-1944), die Lage in einzelnen europäischen Ländern (1926-1936), Ostasien und Südafrika, Waffenlieferungen an den Irak, Verstärkung der deutschen Auslandspropaganda (1941-1943), das Nansen-Komitee für Hilfe für russische Emigranten $(1928,1936)$, deutsche Auslandsvertretungen, die Tätigkeit, insbesondere Veröffentlichungen, ausländischer Vertretungen in Deutschland und das Deutsche Institut für außenpolitische Forschung (19371945).

\subsubsection{Vertretungen der Länder beim Reich}

Da von den Vertretungen Thüringens und Mecklenburgs in Berlin offenbar kein Schriftgut erhalten ist, verbleibt als einzige Behörde dieser Kompetenzsparte die

Ein älterer Teilbestand enthält aus der Zeit nach 1933 u. a. Akten betr. Außenpolitik im allgemeinen (3 Bde, 1919-1935), Saargebiet (1926-1935), Rußland (1920-1934), Orient und Ferner Osten (1921-1934), Innenpolitik, Regierungskrise (1932-1934), Wendenbewegung (1932-1935), Reichsregierung (1926-1934), Pressestimmen zur Reichsreform (1929-1934), Kriegs- und Heeresgesellschaften (7 Bde, 1927-1934), Energieversorgung (1917-1934), Greuelhetze und Boykott deutscher Waren im Ausland (1933/34), Devisenverordnung (1921-1934), Stillegung von Betrieben (1927-1934), Beamte (8 Bde, 1875-1936), Staatsangehörigkeitssachen (1922-1935), Wohlfahrtspflege (1918-1936), Polizei und öffentliche Sicherheit (4 Bde, 1914-1936), Kommunalsachen (1917-1936), Reichsbühnengesetz (1921-1936), Messen und Märkte (1887-1936), Reichssiedlungsgesetz (1932-1936), Land- und Forstwirtschaft (8 Bde, 1869-1936), Medizinalwesen (8 Bde, 1911-1936), Vereine und Parteien (2 Bde, 1922-1936), Presse (2 Bde, 1924-1935), Schule, Kunst und Wissenschaft (12 Bde, 1882-1935), Kirchen (3 Bde, 1914-1936), Rundfunk (1932-1935), Handelsverträge (ca. 20 Bde, 1921-1935, je 1 Bd betr. Handelsverträge mit der Sowjetunion und Beschränkung der Tabakimporte 1933 im ZDM MO, Best. 1349), Bankwesen (5 Bde, 1924-1935), Konsulatswesen (1919-1935), Verkehr (8 Bde, 1924-1935), Internationale Elbekommission (1924-1934), Justiz (ca. 15 Bde, 1910-1935), Hindenburg-Spende (1927-1934), Landesarbeitsamt Sachsen (1930-1934), Reichstreuhänder der Arbeit (1933), Wohnungswesen (6 Bde, 1914-1935), Krankenversicherung (2 Bde, 1931-1935), Statistik (4 Bde, 1887-1936), Verfassung, Bundesrat, 
Reichstag (9 Bde, 1867-1936), Reichs- und Länderfinanzen (ca. 20 Bde, 1872-1936), Wirtschaft und Ernährung (13 Bde, 1914-1936).

Ein anderer Teilbestand umfaßt die 1945 noch kurrenten Akten (früher Rep. 216 des GStA) u. a. über Aufgaben und Tätigkeit der Vertretung allgemein (8 Bde, 1920-1944), Politik (8 Bde, 1920-1942), Wirtschaft und Verkehr (25 Bde, 1926-1940), Wissenschaft, Schulwesen und Kunst (8 Bde, 1916-1943), Ordens- und Titelverleihungen (2 Bde, 19331943), Vereine und Verbände (8 Bde, 1912-1944), Denkschriften (2 Bde, 1934-1939), amtliche Veröffentlichungen (2 Bde, 1933-1939), Staatshaushalt (10 Bde, 1909-1944); Verwaltung, Dienstbetrieb (ca. 30 Bde, 1910-1944), Verwaltung des Dienstgebäudes (17 Bde, 1864-1943), Kassen- und Rechnungssachen (ca. 20 Bde, 1919-1945), Personalangelegenheiten (21 Bde, 1895-1943), Reichsreform (2 Bde, 1932-1940) sowie Behörden und Organisation (4 Bde, 1931-1942, darin: Aufenthalt Mutschmanns in Berlin 19411942). 